\title{
Patterns of physical activity progression in patients
}

\section{with COPD}

Maria Koreny ${ }^{\mathrm{a}, \mathrm{b}, \mathrm{c}}$, , Heleen Demeyer ${ }^{\mathrm{d}, \mathrm{e}, \mathrm{f}}$, Marta Benet ${ }^{\mathrm{a}, \mathrm{b}, \mathrm{c}}$, Ane Arbillaga-Etxarrig ${ }^{\mathrm{g}}$, Eva Balcells $^{\mathrm{b}, \mathrm{h}, \mathrm{i}}$, Anael Barberan-Garciaj, Elena Gimeno-Santos ${ }^{j}$, Nicholas S. Hopkinson ${ }^{\mathrm{k}}$, Corina De Jong ${ }^{\mathrm{l}, \mathrm{m}}$, Niklas Karlsson ${ }^{\mathrm{n}}$, Zafeiris Louvaris ${ }^{\mathrm{d}, \mathrm{o}}$, Michael I. Polkey ${ }^{\mathrm{k}}$, Milo A. Puhan $^{p}$, Roberto A. Rabinovich ${ }^{q}$, Robert Rodríguez-Roisin', Pere Vall-Casas ${ }^{r}$, loannis Vogiatzis $^{\mathrm{o}, \mathrm{s}}$, Thierry Troosters ${ }^{\mathrm{d}, \mathrm{e}}$, Judith Garcia-Aymerich ${ }^{\mathrm{a}, \mathrm{b}, \mathrm{c}, \star}$

a ISGlobal, Barcelona, Spain

b Pompeu Fabra University (UPF), Barcelona, Spain

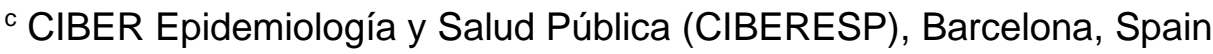

d Department of Rehabilitation Sciences, KU Leuven - University of Leuven, Leuven, Belgium

e Department of Respiratory Diseases, University Hospitals KU Leuven, Leuven, Belgium

f Department of Rehabilitation Sciences, Ghent University, Ghent, Belgium g Physical Activity and Sports Sciences, Faculty of Psychology and Education, University of Deusto, Donostia-San Sebastián, Spain

${ }^{\text {h }}$ CIBER Enfermedades Respiratorias (CIBERES), Madrid, Spain

' Pneumology Department, Institut Hospital del Mar d'Investigacions Mèdiques (IMIM), Hospital del Mar, Barcelona, Spain

j University of Barcelona, Institut d'Investigació Biomèdica August Pi i Sunyer (IDIBAPS), CIBER Enfermedades Respiratorias (CIBERES), Hospital Clínic, Barcelona, Spain 
${ }^{\mathrm{k}}$ National Heart and Lung Institute, Imperial College, Royal Brompton Hospital Campus, London, UK

'Department of General Practice, University Medical Center Groningen, University of Groningen, Groningen, The Netherlands

${ }^{m}$ Groningen Research Institute for Asthma and COPD (GRIAC), University Medical Center Groningen, University of Groningen, Groningen, The Netherlands

${ }^{n}$ Patient Centered Science, BioPharmaceuticals, AstraZeneca R\&D, Gothenburg, Sweden

- First Department of Respiratory Medicine, National and Kapodistrian University of Athens, Athens, Greece

${ }^{\mathrm{P}}$ Epidemiology, Biostatistics and Prevention Institute, University of Zurich, Zurich, Switzerland

`ELEGI Colt Laboratory, Centre for Inflammation Research, The Queen's Medical Research Institute, University of Edinburgh, Edinburgh, Scotland, UK r Universitat Internacional de Catalunya (UIC), Barcelona, Spain

s Department of Sport, Exercise and Rehabilitation, Northumbria University Newcastle, Newcastle, UK

*Correspondence: Dr Judith Garcia-Aymerich

Barcelona Institute of Global Health (ISGlobal)

C/ Doctor Aiguader 88, 08003 Barcelona, Spain

Tel (+34) 932147380

Email: judith.garcia@isglobal.org 


\section{Acknowledgments}

The authors thank Anne-Elie Carsin for the statistical support.

The Urban Training Study Group: ISGlobal, Barcelona: Ane Arbillaga-Etxarri, Marta Benet, Anna Delgado, Judith Garcia-Aymerich, Elena Gimeno-Santos, Jaume TorrentPallicer; FCS Blanquerna, Universitat Ramon Llull, Barcelona: Jordi Vilaró; Servei de Pneumologia, Hospital Clínic de Barcelona, Barcelona: Anael Barberan-Garcia, Robert Rodriguez-Roisín; Hospital del Mar, Institut Hospital del Mar d'Investigacions Mèdiques (IMIM), Barcelona: Eva Balcells, Diego A Rodríguez Chiaradía; Hospital Universitari Germans Trias i Pujol, Badalona: Alicia Marín; Hospital de Mataró, Consorci Sanitari del Maresme, Mataró: Pilar Ortega; Hospital de Viladecans, Viladecans: Nuria Celorrio; Institut Universitari d'Investigació en Atenció Primària Jordi Gol (IDIAP Jordi Gol): Mónica Monteagudo, Nuria Montellà, Laura Muñoz, Pere Toran; Centre d’Atenció Primària Viladecans 2, Institut Català de la Salut, Viladecans: Pere Simonet; Centre d'Atenció Primària Passeig de Sant Joan, Institut Català de la Salut, Barcelona: Carme Jané, Carlos Martín-Cantera; Centre d'Atenció Primària Sant Roc, Institut Català de la Salut, Badalona: Eulàlia Borrell; Universitat Internacional de Catalunya (UIC), Barcelona: Pere Vall-Casas.

The PROactive Consortium members: Almirall, Barcelona, Spain: Nathalie Ivanoff; AstraZeneca AB, Mölndal, Sweden: Niklas Karlsson and Solange Corriol-Rohou; British Lung Foundation, London, UK: Ian Jarrod; Boehringer Ingelheim, NiederIngelheim, Germany: Damijen Erzen; Chiesi Farmaceutici S.A. Parma, Italy: Caterina Brindicci, Tim Higenbottam and Mario Scuri; Choice Healthcare Solutions, Hitchin, UK: Paul McBride; European Respiratory Society, Lausanne, Switzerland: Nadia Kamel; 
GlaxoSmithKline, Uxbridge, UK: Margaret Tabberer; Katholieke Universiteit Leuven, Leuven, Belgium: Thierry Troosters and Fabienne Dobbels; Municipal Institute of Medical Research, Barcelona, Spain: Judith Garcia-Aymerich; Netherlands Asthma Foundation, Amersfoort, The Netherlands: Pim de Boer; Novartis, Basel, Switzerland: Karoly Kulich and Alastair Glendenning; Pfizer Walton Oaks, UK: Katja Rudell and Frederick J. Wilson; Royal Brompton and Harefield NHS Foundation Trust, London, UK: Michael I. Polkey and Nick S. Hopkinson; Thorax Research Foundation, Athens, Greece: loannis Vogiatzis; UCB, Brussels, Belgium: Enkeleida Nikai; University Medical Center, Groningen, The Netherlands: Thys van der Molen and Corina De Jong; University of Edinburgh, Edinburgh, UK: Roberto A. Rabinovich and Bill MacNee; University of Zurich, Zurich, Switzerland: Milo A. Puhan and Anja Frei.

\section{Authors' contribution}

JGA had full access to all of the data in the study and takes responsibility for the integrity of the data and the accuracy of the data analysis. MK, HD and JGA drafted the first version of the manuscript; MK, HD, MB and JGA had full access to the data and were responsible for the statistical analysis; MK, HD, MB, AAE, EB, ABG, EGS, NH, CdJ, NK, ZL, MPo, MPu, RRa, RRo, PVC, IV, TT, JGA contributed to data collection and coordination. All authors 1) provided substantial contributions to the conception or design of the work; or the acquisition, analysis or interpretation of data for the work; 2) drafted or revised the manuscript for important intellectual content; 3) approved the final version; and 4) agreed to be accountable for all aspects of the work.

\section{Declaration of interest}

NK is employed by AstraZeneca. MP reports personal fees from Philips, during the conduct of the study. TT reports lecture fees to his institution from Boehringer Ingelheim, Chiesi Belgium and AstraZeneca outside the submitted work. JGA reports 
payments for consulting and lecture fees to her institution from AstraZeneca and lecture fees from Esteeve, Chiesi and Menarini outside the submitted work. The authors report no other conflict of interest in this work.

\section{Funding information}

The Urban Training study was funded by grants from Fondo de Investigación Sanitaria, Instituto de Salud Carlos III (ISCIII, PI11/01283 and PI14/0419), integrated into Plan Estatal I+D+| 2013-2016 and co-funded by ISCIII-Subdirección General de Evaluación y Fomento de la Investigación and Fondo Europeo de Desarrollo Regional (FEDER); Sociedad Española de Neumología y Cirugía Torácica (SEPAR, 147/2011 and 201/2011), Societat Catalana de Pneumologia (Ajuts al millor projecte en fisioteràpia respiratòria 2013). We acknowledge support from the Spanish Ministry of Science and Innovation through the "Centro de Excelencia Severo Ochoa 2019-2023" Program (CEX2018-000806-S), and support from the Generalitat de Catalunya through the CERCA Program.

The PROactive project was funded by the European Commission Innovative Medicines Initiative Joint Undertaking (IMI JU \# 115011). HD is a post-doctoral research fellow of FWO Vlaanderen. ZL is a post-doctoral fellow of the FWO-Flanders (\#12U5618N).

The funders had no role in study design, data collection and analysis, decision to publish, or preparation of the manuscript.

\section{Ethics approval}

This study was conducted in accordance with the amended Declaration of Helsinki.

Both studies were approved by all local institutional review boards and written informed 
consent, including re-use of data for COPD-related research, was obtained from all patients.

The Urban Training trial was approved by the ethics committees of all participating institutions (Comitè Ėtic d'Investigació Clínica Parc de Salut MAR 2011/4291/l, Comitè Ètic d'Investigació Clínica de I'IDIAP Jordi Gol i Gurina P11/116, Comitè Ėtic d'Investigació Clínica de l'Hospital Universitari de Bellvitge PR197/11, Comitè Ètic d'Investigació Clínica de l'Hospital Universitari Germans Trias i Pujol AC-12-004, Comitè Ėtic d'Investigació Clínica de l'Hospital Clínic de Barcelona 2011/7061, Comitè Ėtic d'Investigació Clínica de l'Hospital de Mataró November 23rd, 2011).

The PROactive study was advised and approved by the PROactive ethics and patient advisory boards, and approved by the local ethics committee at each centre (Commissie medische ethiek van de universitaire ziekenhuizen KU Leuven (Leuven, S55919); Medische ethische toetsingscommissie universitair medisch centrum Groningen (Groningen, Metc 2013.362); RES Committee London-South East (London and Edinburgh, 13/LO/1660); Scientific Council of the 'Sotiria' General Hospital for Chest Diseases (Athens, 27852/7-10-13); Kantonale Ethikkommission Zürich and Ethikkommission Nordwest- und Zentralschweiz (Zurich, KEK-ZH-Nr. 2013-0469).

Prior abstract presentation/ publication: This work was presented at the European Respiratory Society Congress 2019 in Madrid and the abstract was published in the European Respiratory Journal 2019; 54: Suppl. 63, OA5361. 


\section{Abstract}

Introduction: Although mean physical activity in COPD patients declines by 400 to 500 steps/day annually, it is unknown whether the natural progression is the same for all patients. We aimed to identify distinct physical activity progression patterns using a hypothesis-free approach and to assess their determinants.

Methods: We pooled data from two cohorts (usual care arm of Urban Training [NCT01897298] and PROactive initial validation [NCT01388218] studies) measuring physical activity at baseline and 12 months (Dynaport MoveMonitor). We identified clusters (patterns) of physical activity progression (based on levels and changes of steps/day) using k-means, and compared baseline sociodemographic, interpersonal, environmental, clinical and psychological characteristics across patterns.

Results: In 291 COPD patients (mean \pm SD $68 \pm 8$ years, $81 \%$ male, FEV $159 \pm 19 \%$ pred) we identified three distinct physical activity progression patterns: Inactive ( $\mathrm{n}=173$ [59\%], baseline: $4621 \pm 1757$ steps/day, $12-$ month change $(\Delta):-487 \pm 1201$ steps/day), Active Improvers ( $\mathrm{n}=49$ [17\%], baseline: $7727 \pm 3275$ steps/day, $\Delta:+3378 \pm 2203$ steps/day) and Active Decliners ( $\mathrm{n}=69$ [24\%], baseline: $11267 \pm 3009$ steps/day, $\Delta$ : $2217 \pm 2085$ steps/day). After adjustment in a mixed multinomial logistic regression model using Active Decliners as reference pattern, a lower 6-min walking distance (RRR [95\% Cl] 0.94 [0.90-0.98] per 10m, $p=0.001)$ and a higher mMRC dyspnea score (1.71 [1.12-2.60] per 1 point, $\mathrm{p}=0.012)$ were independently related with being Inactive. No baseline variable was independently associated with being an Active Improver. Conclusions: The natural progression in physical activity over time in COPD patients is heterogeneous. While Inactive patients relate to worse scores for clinical COPD characteristics, Active Improvers and Decliners cannot be predicted at baseline. 


\section{Resumen}

Introducción: Aunque la actividad física en pacientes con EPOC declina una media anual de 400-500 pasos/día, se desconoce si esta progresión es igual en todos los pacientes. Este estudio pretendió identificar los patrones de progresión de la actividad física mediante métodos libres de hipótesis y evaluar sus determinantes.

Métodos: Se estudiaron 291 pacientes con EPOC estable (media $\pm D E 68 \pm 8$ años, $81 \%$ hombres, VEMS $59 \pm 19 \%$ pred) de dos cohortes europeas con actividad física basal y a 12 meses (acelerómetro Dynaport MoveMonitor). Se identificaron conglomerados (patrones) de progresión de actividad física basados en los niveles y cambios de pasos/día usando k-means, y se compararon entre patrones las características sociodemográficas, interpersonales, ambientales, clínicas y psicosociales basales. Resultados: Se identificaron tres patrones: Inactivo ( $n=173$ [59\%], basal: $4621 \pm 1757$ pasos/día, cambio en 12 meses $(\Delta)$ : $-487 \pm 1201$ pasos/día), Activo que aumenta ( $\mathrm{n}=49$ [17\%], basal: $7727 \pm 3275$ pasos/día, $\Delta:+3378 \pm 2203$ pasos/día) and Activo que reduce (n=69 [24\%], basal: $11267 \pm 3009$ pasos/día, $\Delta:-2217 \pm 2085$ pasos/día). La distancia en la prueba de la marcha de 6 minutos (6MWD) y la disnea se asociaron independientemente con ser Inactivo: RRR [95\% Cl] 0.94 [0.90-0.98] por cada $10 \mathrm{~m}$ de $6 M W D(p=0.001)$ y $1.71[1.12-2.60]$ por cada punto en la escala mMRC $(p=0.012)$, respectivamente, en comparación con el patrón Activo que reduce. No se encontraron variables basales independientemente asociadas con ser Activo que aumenta.

Conclusiones: La progresión natural de la actividad física en pacientes con EPOC es heterogénea. Mientras que el patrón de pacientes Inactivo se relaciona con peores características clínicas de EPOC, no se pudo predecir la evolución de los Activos a aumentar o reducir. 


\section{Keywords}

COPD, physical activity, patterns of progression, cluster analysis, determinants

\section{Abbreviations}

BMI, body mass index; CAT, COPD assessment test; CCQ, clinical COPD questionnaire; $\mathrm{Cl}$, confidence interval; COPD, chronic obstructive pulmonary disease; C-PPAC, clinical visit_-PROactive physical activity in COPD; FEV1, forced expiratory volume in 1 second; FFMI, fat free mass index; FVC, forced vital capacity; GOLD, global initiative for chronic obstructive lung disease; HAD-A, hospital anxiety and depression scale - anxiety; HAD-D, hospital anxiety and depression scale depression; LABA: long-acting beta 2 -agonists; LAMA: long-acting anti-muscarinics; MET, metabolic equivalent of task; mMRC, modified medical research council dyspnea score; 6MWD, 6-min walking distance; MVPA, moderate to vigorous physical activity; $\mathrm{RRR}$, relative risk ratio; SD, standard deviation. 


\section{Introduction}

Physical activity is a key prognostic factor in chronic obstructive pulmonary disease (COPD), yet poorly understood. COPD patients are less active than healthy controls from the early stages of disease onwards (1-3) and this reduced activity has been associated with impaired prognosis and accelerated progression of COPD $(4,5)$. For this reason, several national and international COPD guidelines recommend encouraging patients to maintain a good physical activity level $(6,7)$.

Despite patients' and health professionals' efforts, physical activity has been shown to exhibit a spontaneous decline of an average of 400 to 500 steps/day per year in COPD patients (8-14). Such observed decline has been related, although not consistently, to lower lung function levels $(10,11)$, the presence of exacerbations $(15-17)$ or the seasonality of testing (eg, decline observed in patients going from summer to winter) $(12,18)$. Given the heterogeneous nature and progression of COPD (19), it can be hypothesized that physical activity progression also displays different patterns, not captured by the mean physical activity values. Two previous studies support this hypothesis by showing distinct physical activity trajectories over 9 months after a pulmonary rehabilitation program $(20,21)$. However, the reported progression in physical activity after rehabilitation programs probably does not reflect how physical activity evolves in the wider COPD population nor in an observational setting, where patients receive a variable combination of pharmacological and non-pharmacological treatments.

We aimed (1) to identify, using a hypothesis-free approach, distinct patterns of natural physical activity progression in COPD patients recruited from diverse settings (primary care, hospital and rehabilitation services) and followed during 12 months; and (2) to 
assess the baseline sociodemographic, interpersonal, environmental, clinical and psychological determinants for the identified patterns. Better understanding of the natural progression of physical activity, of potential distinct patterns and of their determinants could help to individualize strategies to increase (or prevent a decline in) physical activity.

\section{Methods}

\section{Study design and patient population}

This was an observational (no intervention) cohort study of 12-month follow-up including patients from: (1) the usual care arm $(n=205)$ from the Urban Training study (22), that recruited patients from primary care and tertiary hospitals in five Catalan seaside municipalities (Badalona, Barcelona [center and shore areas], Mataró, Viladecans and Gavà); and (2) the clinically stable patients ( $\mathrm{n}=207)$ from the PROactive validation study (23), that recruited patients from primary care settings, rehabilitation centers and tertiary hospitals in five European cities (Athens/Greece, Edinburgh and London/United Kingdom, Groningen/Netherlands, and Leuven/Belgium). Both studies defined COPD according to ATS/ERS (postbronchodilator forced expiratory volume in 1 second $\left(\mathrm{FEV}_{1}\right)$ to forced vital capacity $(\mathrm{FVC})$ ratio $<0.70)(24)$. Patients were included in the present analyses if they had a valid physical activity measure (see below) at baseline and 12-month follow-up.

Both studies were approved by all local institutional review boards and written informed consent, including re-use of data for COPD-related research, was obtained from all patients. 


\section{Physical activity measurements}

Physical activity was objectively measured using the Dynaport MoveMonitor (McRoberts BV, The Hague, The Netherlands) (25) for one week at baseline and follow-up. In Urban Training, patients wore the monitor for 24 hours and data during waking hours (from 07:00 $\mathrm{h}$ to $22: 00 \mathrm{~h}$ ) were retrieved. In PROactive, patients wore the device during waking hours. A valid physical activity measurement was defined as a minimum of three days with at least 8 hours of wearing time within waking hours for both studies (26); details have been previously published $(22,23)$. A physical activity report was provided to patients if requested.

We used step count as the primary outcome to define physical activity progression patterns, and time spent in physical activity of moderate to vigorous intensity (MVPA, $\geq 3$ METs [metabolic equivalents of tasks] min/day), movement intensity $\left(\mathrm{m} / \mathrm{s}^{2}\right)$ during walking, and sedentary time (sum of lying and sitting time, hours/day) as secondary physical activity outcomes to describe patterns. Physical activity experience was assessed by the amount, difficulty and total scores of the Clinical visit-PROactive Physical Activity in COPD (C-PPAC) tool (23).

\section{Other measurements}

We used variables available from both studies (ie exactly the same or equivalent standardized questions and procedures had been used) or variables that were available from one study only but had been related to physical activity or its evolution in the literature: (i) sociodemographic: age, sex, smoking history and education; (ii) interpersonal: marital status, working status, grandparenting and dog walking; (iii) environmental: season of recruitment, average yearly rainfall and urban vulnerability index (a measure of socioeconomic status at the census tract level); (iv) clinical: post- 
bronchodilator $\mathrm{FEV}_{1}$ and FVC, the 6-min walking distance (6MWD) test, the COPD Assessment test (CAT), the Clinical COPD Questionnaire (CCQ), the modified Medical Research Council dyspnea scale (mMRC), the number of acute COPD exacerbations requiring a hospital admission in the previous 12 months and during follow-up, body mass index (BMI) and fat free mass index (FFMI) by physical examination and bioelectrical impedance, comorbidities from medical records, pharmacological treatment for COPD, pulmonary rehabilitation at baseline and follow-up, incident diseases during follow-up, and knowledge of baseline physical activity (ie report on request); and (v) psychological: the Hospital Anxiety (HAD-A) and Depression (HAD-D) scores. Full details on study procedures and quality control have been reported previously $(22,23,27)$.

\section{Statistical analysis}

Sample size calculations, missing data strategy and full statistical analyses are provided in the supplement.

We identified cluster groups (physical activity patterns) using k-means (28), a hypothesis-free method that allowed grouping patients based on the baseline level, the final level and the change in daily step count. To characterize the patterns, we described physical activity and physical activity experience variables according to the cluster groups and compared baseline to follow-up values by paired t-tests.

To assess determinants of physical activity progression patterns, we first compared subjects' characteristics by physical activity patterns and obtained p-values from mixed logistic regression models with random intercepts for study and city area to account for possible heterogeneity in unmeasured characteristics related to study and city area. Then we built a multivariable multinomial regression model using the generalized linear 
latent and mixed model, with also random intercepts for study and city (29). Model building combined step-forward and backward algorithms and we tested goodness of fit of the final model.

As sensitivity analyses, we (1) repeated cluster analysis separately for Urban Training and PROactive; (2) tested the association between the change in daily step count and the change in wearing time overall and per pattern; and (3) repeated the clustering after excluding patients included in pulmonary rehabilitation programs at baseline and/or during follow-up.

All analyses were conducted using Stata/SE 14.2 (StataCorp, College Station, TX, USA).

\section{Results}

From 412 patients at baseline, 291 (71\%) completed the follow-up visit and were included in the current analyses (Figure S1). These patients had a higher proportion of males, better functional status and were more active at baseline than those lost-to follow-up (Table S1). Included patients were $81 \%$ male and had a mean age of 68 years, $\mathrm{FEV}_{1}$ of $59 \%$ predicted, $6 \mathrm{MWD}$ of $477 \mathrm{~m}$, mMRC dyspnea score of 1.3 , and walked 6720 steps/day (Table 1). Compliance with the activity monitor during waking hours was excellent: at baseline median (range) valid days of 7 (3-7) and mean \pm SD wearing hours of $14.6 \pm 0.5$ in Urban Training, and 6 (3-7) days and $14.8 \pm 2.2$ wearing hours in PROactive; and at follow-up, 7 (4-7) days and 14.6 \pm 0.6 wearing hours in Urban Training, and 6 (3-7) days and 14.4 \pm 2.2 wearing hours in PROactive.

At the group level, the step count did not change over 12 months. In the hypothesisfree approach, we identified three cluster groups (three distinct physical activity 
patterns) (Figure 1, Table S2). A first cluster ( $\mathrm{n}=173$ [59\%]), labelled Inactive pattern due to the low step count, walked at baseline mean \pm SD $4621 \pm 1757$ steps/day and decreased their physical activity by $487 \pm 1201$ steps/day over 12 months. A second cluster ( $\mathrm{n}=49[17 \%])$, labelled Active Improvers, walked $7727 \pm 3275$ steps/day at baseline and increased by $3378 \pm 2203$ steps/day. The third cluster $(n=69[24 \%])$, labelled Active Decliners, walked $11267 \pm 3009$ steps/day at baseline and decreased by $2217 \pm 2085$ steps/day. Distribution of MVPA and walking intensity by physical activity pattern followed the same sequence as steps/day, except for walking intensity in Active Improvers that did not change. Sedentary time did not change for Inactive, decreased for Active Improvers and increased moderately for Active Decliners. The physical activity experience as expressed by C-PPAC scores did not change for the Inactive pattern; the Active Improvers increased the C-PPAC scores (ie, increased amount and reduced difficulty); the Active Decliners decreased the C-PPAC amount and total scores while the C-PPAC difficulty score did not change (Figure 2, Table S2).

Patients in the Inactive physical activity pattern had a higher degree of education, a smaller proportion was living with a partner or grandparenting, and they presented with a worse general health status, lower lung function, poorer exercise capacity, worse quality of life and higher dyspnea and depression scores than those in the Active Improvers or Decliners patterns (Table 2). Active Improvers and Decliners were very similar in their baseline characteristics, except for their daily step count.

In the multivariable multinomial logistic regression model we used Active Decliners as the reference pattern to capture both the determinants of being Inactive vs Active and the determinants of being an Active Improver vs Decliner. A lower exercise capacity and a higher mMRC dyspnea score were independently related with being Inactive whereas 
no variable was identified as independently associated with being an Active Improver (Table 3). The final model showed good fit. Sensitivity analyses confirmed the results (Tables S3, S4 and S5).

\section{Discussion}

This study identified, for the first time to our knowledge, the natural progression of physical activity in COPD patients. We used a hypothesis-free approach that allowed the identification of patterns without a priori assumptions about the physical activity changes over time. We found that (1) the natural change in physical activity over time was indeed heterogeneous; (2) the majority of patients (59\%) was inactive at baseline and decreased their physical activity level subsequently; (3) among active individuals some increased and some decreased their physical activity level; and (4) although clinical COPD characteristics were related to the physical activity level at baseline they could not predict subsequent physical activity changes.

A first important finding is that physical activity progression in COPD is heterogeneous. In our 12-month study, mean changes in the full group were virtually zero; however when using hypothesis-free clustering methods, we identified one Inactive pattern which decreased and two Active patterns which increased or decreased physical activity. This observation is in line with previous reports of heterogeneous physical activity progression in patients with rheumatoid arthritis (30). The average lack of 12month change in step count differs from previous studies that showed overall a decrease in physical activity $(8,10,11,13)$. A potential explanation is that most of these studies recruited patients from outpatient or pulmonary clinics, who may have slightly more advanced disease and reduced variability in physical activity and COPD characteristics as compared to our sample including also primary care. Supporting this, the group of patients who started with a lower physical activity $(59 \%)$ was similar in 
their baseline characteristics to previous studies and also had a comparable mean decrease of around 500 steps/day $(10,11)$. Notably, the low overall dyspnea score may have positively influenced the physical activity level of our study population. A second explanation could lie in the high proportion of male subjects and regional differences in physical activity practice (a cohort of patients included in the Mediterranean region (5) had a baseline physical activity comparable to the Urban Training sample). These characteristics of our sample could justify the two patterns with relatively high baseline physical activity and an average small physical activity change.

The second important finding is that there seems to exist a group of COPD patients (our Active Improvers) that spontaneously increase their physical activity over time. Of note, such observed increase of $>3000$ steps/day is remarkably high given that the minimal important difference has been proposed between 600 and 1100 steps/day (31). There are several possibilities that would explain this observed increase. First, some patients could have been inactive at baseline by chance; however, we tested this option against study records by screening for atypical events and it did not hold true. Second, regression to the mean could account for part of the increase, but in our data regression to the mean was estimated to account for maximal $25 \%$ of the effect. Third, changes in daily steps could be due to changes in wearing time, but this was not the case in our study (Table S4). Fourth, patients could have increased their physical activity after participation in rehabilitation programs, but this was dismissed in our analysis (Table S5). Finally, we considered that some patients in the usual care arm of Urban Training could have increased their physical activity due to being enrolled in a physical activity study. However, the proportion of patients from Urban Training was similar between Active Improvers and Active Decliners. Thus, we suggest that some patients do actually increase their physical activity. 
The evolution of other physical activity variables provided complementary information. Time in MVPA and sedentary time (opposite direction) paralleled the progression of step count in all three patterns, supporting previous research that suggested that in COPD patients, physical activity and sedentary time provide information about the same concept (5). We also investigated the progression of physical activity from the perspective of patients. As expected, C-PPAC amount and total scores followed a trend similar to the objectively measured physical activity, as they include steps/day in their calculation. However, C-PPAC difficulty score remained unchanged in Inactive and Active Decliners and increased (ie, less difficulty) in Active Improvers, suggesting that the observed increase in amount could be related to experiencing fewer difficulties (less dyspnea for instance (32)) while being active.

Our third main finding is the impossibility to predict the physical activity progression patterns, despite having included sociodemographic, interpersonal, environmental and psychological characteristics in addition to the typical clinical COPD variables. We found a large set of COPD-related, functional characteristics associated with the Inactive pattern, in accordance with previous, mainly cross-sectional, literature about the determinants of physical activity levels in COPD $(2,4)$. Also higher education levels, lower social support (living alone, not taking care of grandchildren) and higher depression scores related to being in the Inactive pattern, although none of these factors remained in the multivariable model suggesting they were subject to confounding.

Most tellingly, we did not identify any factors that could predict among Active patients, the evolution to Improvers or Decliners. Surprisingly, the presence of severe 
exacerbations during follow-up did not play any role. It could be speculated that our harmonized exacerbation data was not detailed enough to distinguish the severity of exacerbations, the length of hospital stay or the time from the last exacerbation to physical activity assessment at follow-up. We also considered the role of incident comorbidities during follow-up, which could have influenced behavior, but they were not significantly different for the three patterns. Pharmacological treatment for COPD was not different across progression patterns discarding any potential role for treatment inappropriateness. Moreover, we did not find an association between the recruitment season and physical activity progression. This is in line with the hypothesis that the recruitment season, although possibly affecting the baseline levels of physical activity $(12,18,33)$, would not affect the progression pattern during a follow-up of 12 months. Finally, we did not find an effect of accumulated rainfall on physical activity progression, as recently described cross-sectionally in the same PROactive population (14).

Our study has several implications. It adds to the current knowledge that contrary to the general belief not all patients decline but some patients considerably improve their physical activity, which should be confirmed in future research and shows the importance of including a usual care group in intervention studies. The limitation of traditional clinical COPD characteristics to predict physical activity progression suggests that further research should broaden the view and give more attention to interpersonal and environmental factors potentially related to the individual's motivation. As the optimal timing and use of physical activity interventions to improve physical activity (especially in the long term) is still unclear (34), understanding the different COPD progression patterns may help to overcome a one-size-fits-all approach and customize physical activity promotion to reflect different physical activity practices 
and different treatment needs (35). Finally, our results highlight the limitation of using mean population values in phenomena that are heterogeneous in nature.

A major strength of our study is the inclusion of patients across a broad spectrum of disease severities and physical activity in several European cities. This makes our results applicable (i.e., more representative) to a larger COPD population than a single recruitment setting or severity group. In addition, the inclusion of patients from diverse geographic locations allowed us to indirectly control for residual confounding. Moreover, we included some variables beyond the conventional clinical COPD characteristics (36). The use of the hypothesis-free clustering approach allowed us to identify patterns of physical activity progression based on the distribution of the data without prior assumptions.

However, we acknowledge some shortcomings. We had a small sample size for some of the hypothesized determinants of physical activity progression patterns, such as dog walking, current pulmonary rehabilitation and knowledge of baseline physical activity, which precluded our ability to test their role. Similarly, we did not collect information on some physical activity barriers (eg costs or transportation difficulties), which precluded testing their role on physical activity progression. The drop-out was $29 \%$ which is comparable to previous studies $(37,38)$ but the excluded patients had worse functional parameters, and we cannot rule out that they would have presented with a fourth, potentially declining pattern. The two measurement points available for both studies allowed to investigate only linear patterns over time. Having more data points could provide more detailed information on the trajectories. In addition, a longer follow-up would have been desirable, but the 12-month span appears reasonably long to provide this first novel insight into physical activity patterns. Finally, one might argue that 
pooling of the two studies was not appropriate, although our sensitivity analyses showed similar cluster results and characteristics and it resulted in a broad spectrum of physical activity and COPD severity.

In conclusion, the natural change in physical activity over time in COPD patients is heterogeneous and three distinct patterns of physical activity progression have been identified: a predominant Inactive pattern, related to worse scores for clinical COPD characteristics, and two Active patterns, Improvers and Decliners, which cannot be predicted at baseline. 


\section{References}

1. Van Remoortel H, Hornikx M, Demeyer H, Langer D, Burtin C, Decramer M, et al. Daily physical activity in subjects with newly diagnosed COPD. Thorax 2013;68:962-3.

2. Pitta F, Troosters T, Spruit MA, Probst VS, Decramer M, Gosselink R. Characteristics of Physical Activities in Daily Life in Chronic Obstructive Pulmonary Disease. Am J Respir Crit Care Med 2005;171:972-7.

3. Shrikrishna D, Patel M, Tanner RJ, Seymour JM, Connolly BA, Puthucheary ZA, et al. Quadriceps wasting and physical inactivity in patients with COPD. Eur Respir J 2012;40:1115-22.

4. Gimeno-Santos E, Frei A, Steurer-Stey C, De Batlle J, Rabinovich RA, Raste Y, et al. Determinants and outcomes of physical activity in patients with COPD: a systematic review on behalf of PROactive consortium. Thorax 2014;69:731-9.

5. Demeyer H, Donaire-Gonzalez D, Gimeno-Santos E, Ramon MA, De Battle J, Benet M, et al. Physical Activity Is Associated with Attenuated Disease Progression in Chronic Obstructive Pulmonary Disease. Med Sci Sports Exerc $2019 ; 51: 833-40$.

6. Global strategy for the diagnosis, management, and prevention of chronic obstructive pulmonary disease: 2020 REPORT www.goldcopd.org [accessed 12 November 2019].

7. Pleguezuelos E, Gimeno-Santos E, Hernández C, Mata M del C, Palacios L, Piñera P, et al. Recommendations on Non-Pharmacological Treatment in Chronic Obstructive Pulmonary Disease From the Spanish COPD Guidelines 
(GesEPOC 2017). Arch Bronconeumol 2018;54:568-75.

8. Waschki B, Kirsten AM, Holz O, Mueller K-C, Schaper M, Sack A-L, et al. Disease Progression and Changes in Physical Activity in Patients with Chronic Obstructive Pulmonary Disease. Am J Respir Crit Care Med 2015;192:295-306.

9. Agarwal V, Tetenta S, Bautista J, ZuWallack R, Lahiri B. Longitudinal changes in directly measured physical activity in patients with chronic obstructive pulmonary disease. J Cardiopulm Rehabil Prev 2012;32:292-5.

10. Clarenbach CF, Sievi NA, Haile SR, Brack T, Brutsche MH, Frey M, et al. Determinants of annual change in physical activity in COPD. Respirology 2017;22:1133-9.

11. Sievi NA, Brack T, Brutsche MH, Frey M, Irani S, Leuppi JD, et al. Physical activity declines in COPD while exercise capacity remains stable: A longitudinal study over 5 years. Respir Med 2018;141:1-6.

12. Moy ML, Danilack VA, Weston NA, Garshick E. Daily step counts in a US cohort with COPD. Respir Med 2012;106:962-9.

13. Troosters T, Blondeel A, Rodrigues FM, Janssens W, Demeyer H. Strategies to Increase Physical Activity in Chronic Respiratory Diseases. Clin Chest Med 2019;40:397-404

14. Boutou AK, Raste Y, Demeyer H, Troosters T, Polkey MI, Vogiatzis I, et al. Progression of physical inactivity in COPD patients: the effect of time and climate conditions - a multicenter prospective cohort study. Int J Chron Obstruct Pulmon Dis 2019;14:1979-92.

15. Alahmari AD, Patel AR, Kowlessar BS, Mackay AJ, Singh R, Wedzicha JA, et al. 
Daily activity during stability and exacerbation of chronic obstructive pulmonary disease. BMC Pulm Med 2014;14:98:1-8.

16. Demeyer H, Costilla-frias M, Louvaris Z, Gimeno-Santos E, Tabberer M, Rabinovich RA, et al. Both moderate and severe exacerbations accelerate physical activity decline in COPD patients. Eur Respir J 2018;51:1702110.

17. Sievi NA, Kohler M, Thurnheer R, Leuppi JD, Irani S, Frey M, et al. No impact of exacerbation frequency and severity on the physical activity decline in COPD: a long-term observation. Int J Chron Obstruct Pulmon Dis 2019; Volume 14:431-7.

18. Couto Furlanetto K, Demeyer H, Sant'anna T, Aparecida Hernandes N, Augusto Camillo C, Serra Pons I, et al. Physical Activity of Patients with COPD from Regions with Different Climatic Variations Physical Activity of Patients with COPD from Regions with Different Climatic Variations. COPD J Chronic Obstr Pulm Dis 2017;14:276-83.

19. Agustí A, Hogg JC. Update on the Pathogenesis of Chronic Obstructive Pulmonary Disease. N Engl J Med 2019;381:1248-56.

20. Saunders TJ, Dechman G, Hernandez P, Spence JC, Rhodes RE, McGannon K, et al. Distinct Trajectories of Physical Activity among Patients with COPD during and after Pulmonary Rehabilitation. COPD J Chronic Obstr Pulm Dis 2015;12:539-45.

21. Soicher JE, Mayo NE, Gauvin L, Hanley JA, Bernard S, Maltais F, et al. Trajectories of endurance activity following pulmonary rehabilitation in COPD patients. Eur Respir J 2012;39:272-8.

22. Arbillaga-Etxarri A, Gimeno-Santos E, Barberan-Garcia A, Balcells E, Benet M, 
Borrell E, et al. Long-term efficacy and effectiveness of a behavioural and community-based exercise intervention (Urban Training) to increase physical activity in patients with COPD: a randomised controlled trial. Eur Respir J 2018;52:1800063.

23. Gimeno-Santos E, Raste Y, Demeyer H, Louvaris Z, De Jong C, Rabinovich RA, et al. The PROactive instruments to measure physical activity in patients with chronic obstructive pulmonary disease. Eur Respir J 2015;46:988-1000.

24. Celli BR, Macnee W, Agusti A, Anzueto A, Berg B, Buist AS, et al. Standards for the diagnosis and treatment of patients with COPD: a summary of the ATS/ERS position paper. Eur Respir J 2004;23:932-46.

25. Rabinovich RA, Louvaris Z, Raste Y, Langer D, Van Remoortel H, Giavedoni S, et al. Validity of physical activity monitors during daily life in patients with COPD. Eur Respir J 2013;42:1205-15.

26. Demeyer H, Burtin C, Van Remoortel H, Hornikx M, Langer D, Decramer M, et al. Standardizing the analysis of physical activity in patients with COPD following a pulmonary rehabilitation program. Chest 2014;146:318-27.

27. Arbillaga-Etxarri A, Gimeno-Santos E, Barberan-Garcia A, Benet M, Borrell E, Dadvand $\mathrm{P}$, et al. Socio-environmental correlates of physical activity in patients with chronic obstructive pulmonary disease (COPD). Thorax 2017;0:1-7.

28. Genolini, Christophe Falissard B. KmL: k-means for longitudinal data. Comput Stat 2010;25:317-328.

29. Rabe-Hesketh S, Skrondal A, Pickles A. Maximum likelihood estimation of limited and discrete dependent variable models with nested random effects. $J$ 
Econom 2005;128:301-23.

30. Demmelmaier I, Dufour AB, Nordgren B, Opava CH. Trajectories of Physical Activity Over Two Years in Persons With Rheumatoid Arthritis. Arthritis Care Res 2016;68:1069-77.

31. Demeyer H, Burtin C, Hornikx M, Camillo CA, Van Remoortel H, Langer D, et al. The Minimal Important Difference in Physical Activity in Patients with COPD. PLoS One 2016;11:e0154587.

32. Dubé BP, Vermeulen F, Laveneziana P. Exertional Dyspnoea in Chronic Respiratory Diseases: From Physiology to Clinical Application. Arch Bronconeumol 2017;53:62-70.

33. Hoaas H, Zanaboni P, Hjalmarsen A, Morseth B, Dinesen B, Burge AT, et al. Seasonal variations in objectively assessed physical activity among people with COPD in two Nordic countries and Australia: a cross-sectional study. Int $\mathrm{J}$ Chron Obstruct Pulmon Dis 2019;Volume 14:1219-28.

34. Burge AT, Cox NS, Abramson MJ, Holland AE. Interventions for promoting physical activity in people with chronic obstructive pulmonary disease (COPD). Cochrane Database Syst Rev 2020; Issue 4. Art. No.: CD012626.

35. Miravitlles M, Troosters T, Janssens W, Ancochea J. Multidisciplinary Perspectives on the Importance of Physical Activity in COPD. Arch Bronconeumol 2019;55:551-2.

36. Bauman AE, Reis RS, Sallis JF, Wells JC, F Loos RJ, Martin BW, et al. Correlates of physical activity: why are some people physically active and others not? Lancet 2012;380:258-71. 
37. Coultas DB, Jackson BE, Russo R, Peoples J, Sloan J, Singh KP, et al. A Lifestyle Physical Activity Intervention for Patients with Chronic Obstructive Pulmonary Disease A Randomized Controlled Trial. Ann Am Thorac Soc 2016;13:617-26.

38. Altenburg WA, Ten Hacken NHT, Bossenbroek L, Kerstjens HAM, De Greef MHG, Wempe JB. Short- and long-term effects of a physical activity counselling programme in COPD: A randomized controlled trial. Respir Med 2015;109:11221. 
Table 1 Patient characteristics at baseline and at 12-month follow-up for all patients $(\mathrm{n}=291)$ and by study group (Urban Training and PROactive study).

\begin{tabular}{|c|c|c|c|}
\hline & All patients & $\begin{array}{l}\text { Urban } \\
\text { Training } \\
\text { study }\end{array}$ & $\begin{array}{l}\text { PROactive } \\
\text { study }\end{array}$ \\
\hline & $\begin{array}{l}n=291 \\
(100 \%)\end{array}$ & $\begin{array}{c}n=148^{a} \\
(51 \%)\end{array}$ & $\begin{array}{c}n=143^{a} \\
(49 \%)\end{array}$ \\
\hline \multicolumn{4}{|l|}{ Sociodemographic } \\
\hline Age (years) & $68 \pm 8$ & $69 \pm 8$ & $67 \pm 8$ \\
\hline Sex (men) & $237(81)$ & $130(88)$ & $107(75)$ \\
\hline Current smoker & $52(18)$ & $30(20)$ & $22(15)$ \\
\hline Pack-years & $58 \pm 41$ & $60 \pm 45$ & $56 \pm 37$ \\
\hline Education, high school or higher & $168(58)$ & $49(33)$ & $119(83)$ \\
\hline \multicolumn{4}{|l|}{ Interpersonal } \\
\hline Living with a partner ${ }^{\mathrm{b}}$ & $216(74)$ & $124(84)$ & $92(65)$ \\
\hline Active worker ${ }^{\mathrm{C}}$ & $36(12)$ & $16(11)$ & $20(14)$ \\
\hline Grandparenting $^{d}$ & $67(45)$ & $67(45)$ & - \\
\hline Dog walking $^{d}$ & $20(14)$ & $20(14)$ & - \\
\hline \multicolumn{4}{|l|}{ Environmental } \\
\hline \multicolumn{4}{|l|}{ Recruitment season } \\
\hline Spring & $35(12)$ & $35(24)$ & $0(0)$ \\
\hline Summer & $58(20)$ & $15(10)$ & $43(30)$ \\
\hline Fall & $154(53)$ & $54(36)$ & $100(70)$ \\
\hline Winter & $44(15)$ & $44(30)$ & $0(0)$ \\
\hline Average rainfall $(\mathrm{h} / \text { day })^{e, f}$ & $\begin{array}{c}0.62 \\
(0.30-1.13)\end{array}$ & (. & $\begin{array}{c}0.62 \\
(0.30-1.13)\end{array}$ \\
\hline Urban vulnerability index (from 0 -lowest to 1 -highest) ${ }^{\mathrm{d}, \mathrm{g}}$ & $0.637 \pm 0.175$ & $0.637 \pm 0.175$ & - \\
\hline \multicolumn{4}{|l|}{ Clinical } \\
\hline $\mathrm{FEV}_{1}(\%$ predicted $)$ & $58.6 \pm 19.3$ & $58.2 \pm 17.6$ & $59.0 \pm 21.0$ \\
\hline $\mathrm{FEV}_{1} / \mathrm{FVC}$ ratio & $0.51 \pm 0.13$ & $0.55 \pm 0.12$ & $0.48 \pm 0.13$ \\
\hline \multicolumn{4}{|l|}{ Airflow limitation severity (post-bronchodilator $\mathrm{FEV}_{1}$ ) } \\
\hline GOLD 1: Mild $\left(\mathrm{FEV}_{1} \geq 80 \%\right.$ predicted $)$ & $39(13)$ & $15(10)$ & $24(17)$ \\
\hline GOLD 2: Moderate $\left(50 \% \leq \mathrm{FEV}_{1}<80 \%\right.$ predicted $)$ & $147(51)$ & $80(54)$ & $67(47)$ \\
\hline GOLD 3: Severe $\left(30 \% \leq \mathrm{FEV}_{1}<50 \%\right.$ predicted $)$ & $88(30)$ & $45(30)$ & $43(30)$ \\
\hline GOLD 4: Very Severe (FEV $1<30 \%$ predicted) & $17(6)$ & $8(6)$ & $9(6)$ \\
\hline 6MWD (meters) & $477 \pm 103$ & $501 \pm 83$ & $452 \pm 116$ \\
\hline CAT score $(0-40)$ & $12.9 \pm 7.6$ & $12.2 \pm 7.6$ & $13.6 \pm 7.5$ \\
\hline CCQ score $(0-6)$ & $1.55 \pm 0.98$ & $1.40 \pm 0.95$ & $1.70 \pm 0.98$ \\
\hline C-PPAC amount score $(0-100)$ & $69.0 \pm 15.8$ & $74.7 \pm 14.9$ & $63.8 \pm 14.9$ \\
\hline C-PPAC difficulty score $(0-100)$ & $78.4 \pm 14.5$ & $82.7 \pm 13.4$ & $74.5 \pm 14.5$ \\
\hline C-PPAC total score $(0-100)$ & $73.7 \pm 12.8$ & $78.7 \pm 11.5$ & $69.2 \pm 12.3$ \\
\hline mMRC score $(0-4)$ & $1.3 \pm 0.9$ & $1.1 \pm 0.8$ & $1.5 \pm 1.0$ \\
\hline $\begin{array}{l}\text { Any COPD exacerbation with hospital admission in previous } 12 \\
\text { months }\end{array}$ & $34(12)$ & $12(8)$ & $22(15)$ \\
\hline $\operatorname{BMl}\left(\mathrm{kg} / \mathrm{m}^{2}\right)$ & $27.6 \pm 4.6$ & $28.3 \pm 4.6$ & $26.8 \pm 4.6$ \\
\hline FFMI $\left(\mathrm{kg} / \mathrm{m}^{2}\right)$ & $19.0 \pm 3.0$ & $19.6 \pm 3.2$ & $18.4 \pm 2.8$ \\
\hline Cardiovascular disease ${ }^{h}$ & $176(60)$ & $90(61)$ & $86(60)$ \\
\hline Ischemic heart disease ${ }^{h}$ & $29(10)$ & $13(9)$ & $16(11)$ \\
\hline Diabetes mellitus ${ }^{\mathrm{h}}$ & $51(18)$ & $38(26)$ & $13(9)$ \\
\hline LABA or LAMA, alone & $41(14)$ & $23(16)$ & $18(13)$ \\
\hline Inhaled corticosteroid with LABA and/or LAMA & $179(62)$ & $80(54)$ & $99(71)$ \\
\hline Pulmonary rehabilitation at baseline & $15(5)$ & $6(4)$ & $9(6)$ \\
\hline Knowledge of baseline PA & $19(7)$ & $19(13)$ & $0(0)$ \\
\hline \multicolumn{4}{|l|}{ Psychological } \\
\hline Anxiety (HAD-A, 0-21) & $5 \pm 4$ & $5 \pm 4$ & $5 \pm 4$ \\
\hline Depression (HAD-D, 0-21) & $4 \pm 3$ & $3 \pm 3$ & $5 \pm 3$ \\
\hline \multicolumn{4}{|l|}{ Physical activity } \\
\hline Step count (steps/day) & $6720 \pm 3667$ & $7783 \pm 3847$ & $5619 \pm 3121$ \\
\hline $\begin{array}{l}\text { Time in moderate-to-vigorous physical activity ( } \geq 3 \text { METs; } \\
\min / \text { day) }\end{array}$ & $99.4 \pm 45.3$ & $109.1 \pm 45.7$ & $89.4 \pm 42.8$ \\
\hline
\end{tabular}


Any COPD exacerbation with hospital admission during follow-up

Notes: Data are presented as $\mathrm{n}(\%)$, mean \pm SD or median (interquartile range)

aSome variables have missing values, as follows. Urban Training: 1 in education, 25 in C-PPAC scores, 1 in any COPD exacerbation with hospital admission in previous 12 months, 18 in FFMI, 2 in HAD anxiety and depression, 5 in any COPD exacerbation with hospital admission during follow-up, 2 in pulmonary rehabilitation during follow-up; PROactive: 1 in living with a partner, 21 in average rainfall, 1 in CAT score, 1 in CCQ score, 6 in C-PPAC scores, 8 in FFMI, 3 in LABA or LAMA, alone, 3 in inhaled corticosteroid with LABA and/or LAMA, 1 in HAD anxiety and depression, 3 in pulmonary rehabilitation during follow-up.

${ }^{\mathrm{b}}$ marital status: living with a partner vs single, widowed or divorced.

cworking status: active worker (working full-time or part-time) vs. unemployed, housework or retired.

donly available for Urban Training.

enly available for PROactive.

faverage rainfall was calculated as the mean of the measurements at baseline, 6 and 12 months.

${ }^{9}$ The urban vulnerability index is a measure of socioeconomic status at the census tract level that combines demographic, economic, residential and subjective indicators, and ranges from lowest [0] to highest [1] level of neighborhood vulnerability.

hICD10 codes: 100 to 199 for cardiovascular diseases; I20 to I25 for ischemic heart disease, E14 for diabetes mellitus. incident comorbidities included ICD10 codes C00 to N99.

Abbreviations: $F E V_{1}$ : forced expiratory volume in 1 second; FVC: forced vital capacity; GOLD: Global Initiative for Chronic Obstructive Lung Disease; 6MWD: 6-min walking distance; CAT: COPD Assessment Test; CCQ: Clinical COPD Questionnaire; C-PPAC: Clinical visit—PROactive Physical Activity in COPD (higher numbers indicate a better score); mMRC: modified Medical Research Council; BMI: body mass index; FFMI: fat free mass index; LABA: long-acting beta $2^{-}$ agonists; LAMA: long-acting anti-muscarinics; HAD-A: Hospital Anxiety and Depression scale - Anxiety; HAD-D: Hospital Anxiety and Depression scale - Depression; MET: metabolic equivalent of task. 
Table 2 Patient characteristics by physical activity progression pattern (Inactive, Active Improvers and Active Decliners) in 291 COPD patients.

\begin{tabular}{|c|c|c|c|c|c|}
\hline & Inactive & $\begin{array}{c}\text { Active } \\
\text { Improvers }\end{array}$ & $\begin{array}{c}\text { Active } \\
\text { Decliners }\end{array}$ & $\begin{array}{l}\text { p-value for } \\
\text { Inactive vs } \\
\text { Active } \\
\text { Improvers } \\
\text { and } \\
\text { Decliners }\end{array}$ & $\begin{array}{c}\text { p-value } \\
\text { for Active } \\
\text { Improvers } \\
\text { vs } \\
\text { Decliners }^{b}\end{array}$ \\
\hline & $\begin{array}{c}n=173^{a} \\
(59 \%)\end{array}$ & $\begin{array}{l}n=49^{a} \\
(17 \%)\end{array}$ & $\begin{array}{c}n=69^{a} \\
(24 \%)\end{array}$ & & \\
\hline Urban Training study & $59(34)$ & $39(80)$ & $50(72)$ & & \\
\hline PROactive study & $114(66)$ & $10(20)$ & $19(28)$ & & \\
\hline \multicolumn{6}{|l|}{ Sociodemographic } \\
\hline Age (years) & $68 \pm 8$ & $69 \pm 9$ & $67 \pm 7$ & 0.282 & 0.079 \\
\hline Sex (men) & $137(79)$ & $41(84)$ & $59(86)$ & 0.931 & 0.789 \\
\hline Current smoker & $33(19)$ & $5(10)$ & $14(20)$ & 0.152 & 0.152 \\
\hline Pack-years & $60 \pm 38$ & $63 \pm 52$ & $49 \pm 40$ & 0.187 & 0.082 \\
\hline $\begin{array}{l}\text { Education, high school or } \\
\text { higher } \\
\text { Interpersonal }\end{array}$ & $124(72)$ & $20(42)$ & $24(35)$ & 0.006 & 0.452 \\
\hline Living with a partner ${ }^{c}$ & $115(66)$ & $42(88)$ & $59(86)$ & 0.017 & 0.714 \\
\hline Active worker ${ }^{d}$ & $18(10)$ & $6(12)$ & $12(17)$ & 0.088 & 0.454 \\
\hline Grandparenting $^{e}$ & $20(34)$ & $21(54)$ & $26(52)$ & 0.039 & 0.863 \\
\hline \multicolumn{6}{|l|}{ Environmental } \\
\hline Average rainfall $(\mathrm{h} / \text { day })^{\mathrm{f}, \mathrm{g}}$ & $\begin{array}{c}0.63 \\
(0.33-1.13)\end{array}$ & $\begin{array}{c}0.90 \\
(0.57-1.47)\end{array}$ & $\begin{array}{c}0.33 \\
(0.23-1.00)\end{array}$ & 0.877 & 0.329 \\
\hline $\begin{array}{l}\text { Urban vulnerability index (from } \\
0 \text {-lowest to } 1 \text {-highest) } \text { (,h }^{\text {en }}\end{array}$ & $0.646 \pm 0.176$ & $0.613 \pm 0.200$ & $0.646 \pm 0.153$ & 0.312 & 0.369 \\
\hline \multicolumn{6}{|l|}{ Clinical } \\
\hline $\mathrm{FEV}_{1}(\%$ predicted $)$ & $55.9 \pm 19.8$ & $62.9 \pm 15.8$ & $62.4 \pm 19.5$ & 0.001 & 0.875 \\
\hline $\mathrm{FEV}_{1} / \mathrm{FVC}$ ratio & $0.48 \pm 0.14$ & $0.55 \pm 0.11$ & $0.55 \pm 0.11$ & 0.004 & 0.904 \\
\hline 6MWD (meters) & $446 \pm 105$ & $521 \pm 90$ & $524 \pm 78$ & $<0.001$ & 0.861 \\
\hline CAT score $(0-40)$ & $14.2 \pm 7.7$ & $11.5 \pm 7.3$ & $10.5 \pm 6.6$ & 0.002 & 0.435 \\
\hline CCQ score $(0-6)$ & $1.74 \pm 0.97$ & $1.23 \pm 0.91$ & $1.29 \pm 0.93$ & 0.001 & 0.780 \\
\hline $\begin{array}{l}\text { C-PPAC difficulty score } \\
(0-100)^{i}\end{array}$ & $74.9 \pm 14.7$ & $82.6 \pm 13.6$ & $84.8 \pm 11.6$ & $<0.001$ & 0.380 \\
\hline mMRC score $(0-4)$ & $1.5 \pm 1.0$ & $1.0 \pm 0.8$ & $0.9 \pm 0.7$ & $<0.001$ & 0.329 \\
\hline $\begin{array}{l}\text { Any COPD exacerbation with } \\
\text { hospital admission in previous } \\
12 \text { months }\end{array}$ & $24(14)$ & $4(8)$ & $6(9)$ & 0.517 & 0.918 \\
\hline $\mathrm{BMI}\left(\mathrm{kg} / \mathrm{m}^{2}\right)$ & $27.6 \pm 5.0$ & $27.5 \pm 3.9$ & $27.5 \pm 4.2$ & 0.139 & 0.999 \\
\hline FFMI $\left(\mathrm{kg} / \mathrm{m}^{2}\right)$ & $18.9 \pm 3.0$ & $19.3 \pm 2.9$ & $19.0 \pm 3.1$ & 0.650 & 0.591 \\
\hline Cardiovascular disease & $109(63)$ & $28(57)$ & $39(57)$ & 0.221 & 0.930 \\
\hline Ischemic heart disease ${ }^{\mathrm{j}}$ & $18(10)$ & $5(10)$ & $6(9)$ & 0.898 & 0.807 \\
\hline Diabetes mellitus ${ }^{j}$ & $23(13)$ & $11(22)$ & $17(25)$ & 0.412 & 0.786 \\
\hline LABA or LAMA, alone & $24(14)$ & $7(14)$ & $10(15)$ & 0.796 & 0.949 \\
\hline $\begin{array}{l}\text { Inhaled corticosteroid with } \\
\text { LABA and/or LAMA }\end{array}$ & $115(67)$ & $28(57)$ & $36(53)$ & 0.311 & 0.658 \\
\hline \multicolumn{6}{|l|}{ Psychological } \\
\hline Anxiety (HAD-A, 0-21) & $5 \pm 4$ & $5 \pm 3$ & $5 \pm 4$ & 0.755 & 0.774 \\
\hline Depression (HAD-D, 0-21) & $5 \pm 3$ & $3 \pm 3$ & $3 \pm 3$ & 0.009 & 0.992 \\
\hline \multicolumn{6}{|l|}{ Follow-up data } \\
\hline $\begin{array}{l}\text { Any COPD exacerbation with } \\
\text { hospital admission during } \\
\text { follow-up }\end{array}$ & $19(11)$ & $4(8)$ & $5(7)$ & 0.759 & 0.846 \\
\hline $\begin{array}{l}\text { Any incident comorbidity } \\
\text { during follow-up }{ }^{\mathrm{e}, \mathrm{k}}\end{array}$ & $10(17)$ & $10(26)$ & $14(28)$ & 0.191 & 0.804 \\
\hline
\end{tabular}

Notes: Data are presented as $n(\%)$, mean \pm SD or median (interquartile range). 
aSome variables have missing values, as follows. Inactive: 15 in average rainfall, 1 in CAT total, 1 in CCQ score, 14 in C-PPAC difficulty score, 17 in FFMI, 2 in LABA or LAMA, alone, 2 in inhaled corticosteroid with LABA and/or LAMA, 1 in $\mathrm{HAD}$ anxiety and depression, 3 in any COPD exacerbation with hospital admission during follow-up; Active Improvers: 1 in education, 1 in living with a partner, 2 in average rainfall, 5 in C-PPAC difficulty score, 4 in FFMI, 1 in HAD anxiety and depression, 1 in any COPD exacerbation with hospital admission during follow-up; Active Decliners: 4 in average rainfall, 12 in C-PPAC difficulty score, 1 in any COPD exacerbation with hospital admission in previous 12 months, 5 in FFMI, 1 in LABA or LAMA, alone, 1 in inhaled corticosteroid with LABA and/or LAMA, 1 in HAD anxiety and depression, 1 in any COPD exacerbation with hospital admission during follow-up.

${ }^{b} p$-value from mixed logistic regression models with random effects for study (UT and PROactive) and city area (Badalona, Barcelona-center, Barcelona-shore, Mataró, Viladecans/Gavà, Athens, Edinburgh, Groningen, Leuven, London).

${ }^{\mathrm{C}}$ marital status: living with a partner vs single, widowed or divorced.

dworking status: active worker (working full-time or part-time) vs. unemployed, housework or retired.

eonly available for Urban Training.

'only available for PROactive.

gaverage rainfall was calculated as the mean of the measurements at baseline, 6 and 12 months.

"The urban vulnerability index is a measure of socioeconomic status at the census tract level that combines demographic, economic, residential and subjective indicators, and ranges from lowest [0] to highest [1] level of neighborhood vulnerability.

'only C-PPAC difficulty is provided as C-PPAC amount and total score include steps/day which were used for the generation of the PA patterns and therefore cannot be assessed as predictors.

IICD10 codes: 100 to 199 for cardiovascular diseases; I20 to I25 for ischemic heart disease, E14 for diabetes mellitus. kincident comorbidities included ICD10 codes C00 to N99.

Abbreviations: $\mathrm{FEV}_{1}$ : forced expiratory volume in 1 second; FVC: forced vital capacity; 6MWD: 6-min walking distance; CAT: COPD Assessment Test; CCQ: Clinical COPD Questionnaire; C-PPAC: Clinical visit-PROactive Physical Activity in COPD (higher numbers indicate a better score); mMRC: modified Medical Research Council; BMl: body mass index; FFMI: fat free mass index; LABA: long-acting beta 2 -agonists; LAMA: long-acting anti-muscarinics; HAD-A: Hospital Anxiety and Depression scale - Anxiety; HAD-D: Hospital Anxiety and Depression scale - Depression. 
Table 3 Adjusted predictive factors for Inactive and Active Improvers vs Active Decliners in 291 COPD patients.

\begin{tabular}{|c|c|c|c|c|c|}
\hline & \multirow{2}{*}{$\begin{array}{c}\text { Active Decliners } \\
\text { RRR }(95 \% \mathrm{Cl})\end{array}$} & \multicolumn{2}{|c|}{ Inactive } & \multicolumn{2}{|c|}{ Active Improvers } \\
\hline & & RRR (95\% Cl) & p-value ${ }^{a}$ & $\operatorname{RRR}(95 \% \mathrm{Cl})$ & p-value ${ }^{a}$ \\
\hline 6MWD (per 10m) & 1.00 (ref) & $\begin{array}{c}0.94 \\
(0.90-0.98)\end{array}$ & 0.001 & $\begin{array}{c}1.00 \\
(0.96-1.05)\end{array}$ & 0.868 \\
\hline mMRC score (per 1 point) & 1.00 (ref) & $\begin{array}{c}1.71 \\
(1.12-2.60)\end{array}$ & 0.012 & $\begin{array}{c}1.23 \\
(0.73-2.07)\end{array}$ & 0.437 \\
\hline
\end{tabular}

Notes: ap-value from multinomial regression model with random effects for study (UT and PROactive) and city area (Badalona, Barcelona-center, Barcelona-shore, Mataró, Viladecans/Gavà, Athens, Edinburgh, Groningen, Leuven, London).

Abbreviations: RRR: relative risk ratio; Cl: confidence interval. 6MWD: 6-min walking distance; mMRC: modified Medical Research Council. 
Figure 1 Physical activity variables at baseline and at 12-month follow-up, overall and by PA progression pattern (Inactive, Active Improvers and Active Decliners).

Notes: Data are presented as mean $\pm S E$ (specific numbers are presented in Table S2). ${ }^{*} p$-value $\leq 0.05$.

Abbreviations: MVPA: moderate-to-vigorous physical activity; MET: metabolic equivalent of task. 
All patients
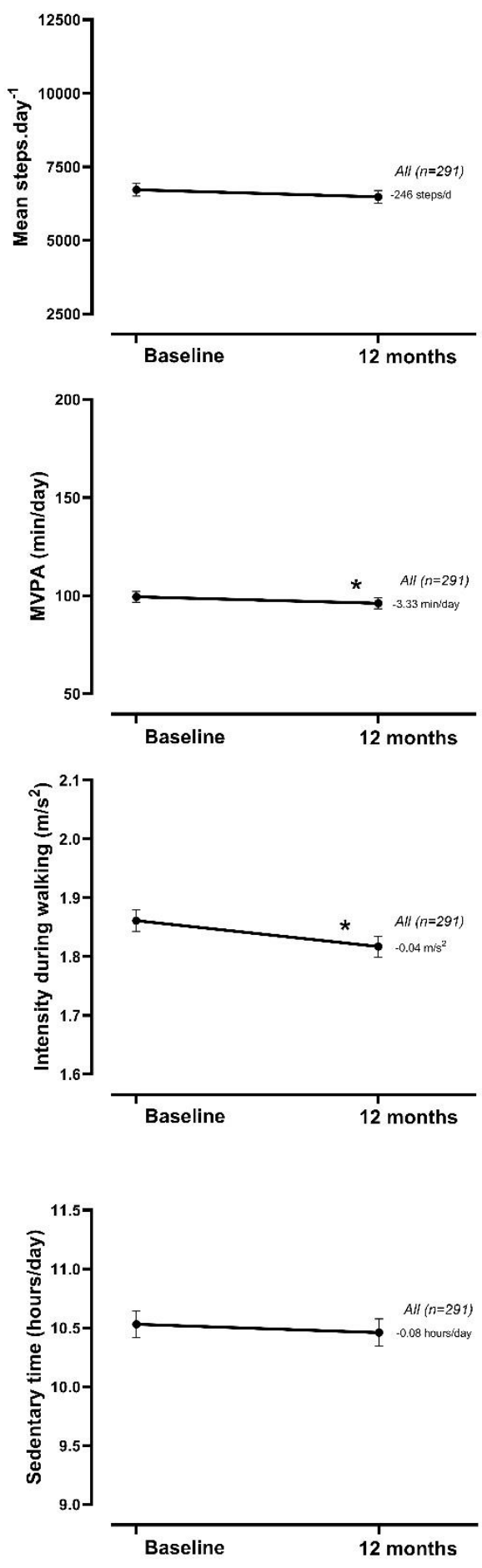

\section{By PA progression patterns}
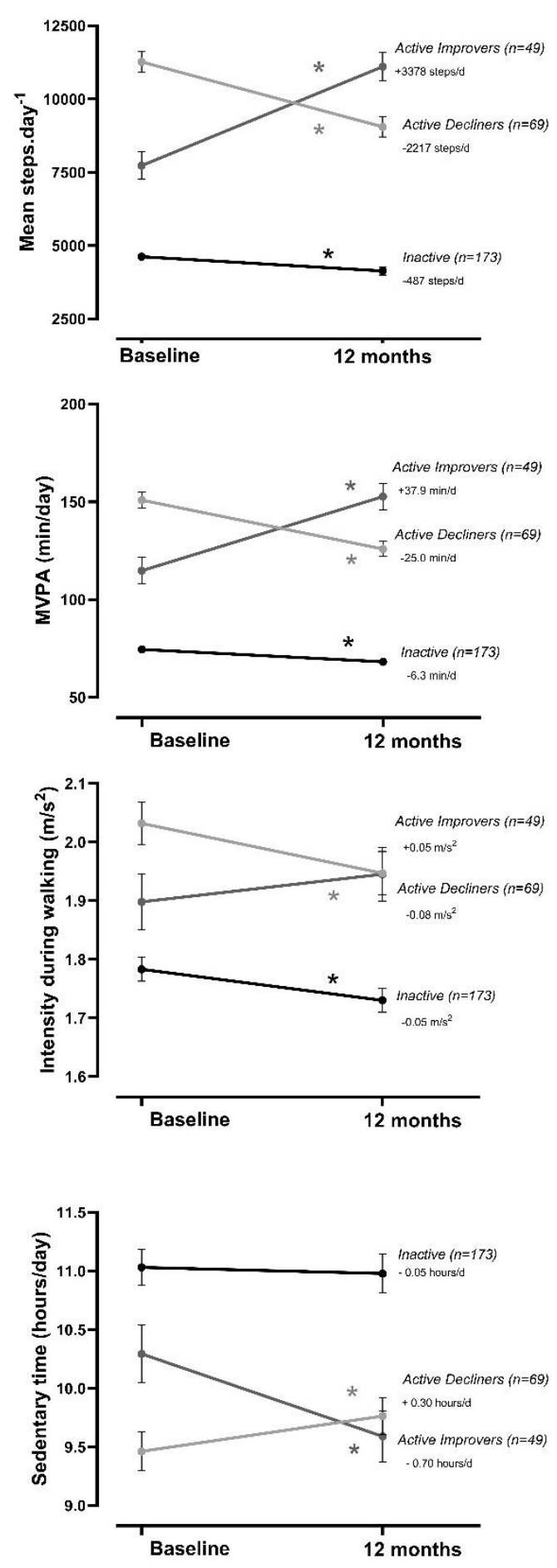
Figure 2 Physical activity experience variables at baseline and at 12-month follow-up, overall and by PA progression pattern (Inactive, Active Improvers and Active Decliners).

Notes: Data are presented as mean $\pm S E$ (specific numbers are presented in Table S2). ${ }^{*} p$-value $\leq 0.05$.

Abbreviations: C-PPAC: Clinical visit-PROactive Physical Activity in COPD (higher numbers indicate a better score). C-PPAC variables have 87 missing values: 38 in Inactive, 21 in Active Improvers, and 28 in Active Decliners. 


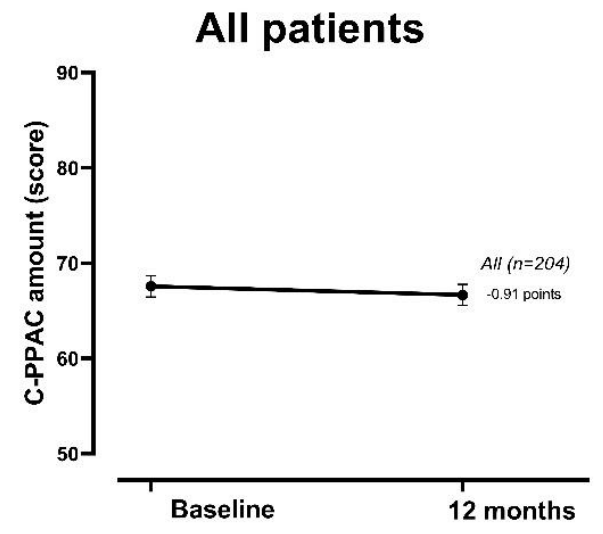

\section{By PA progression patterns}
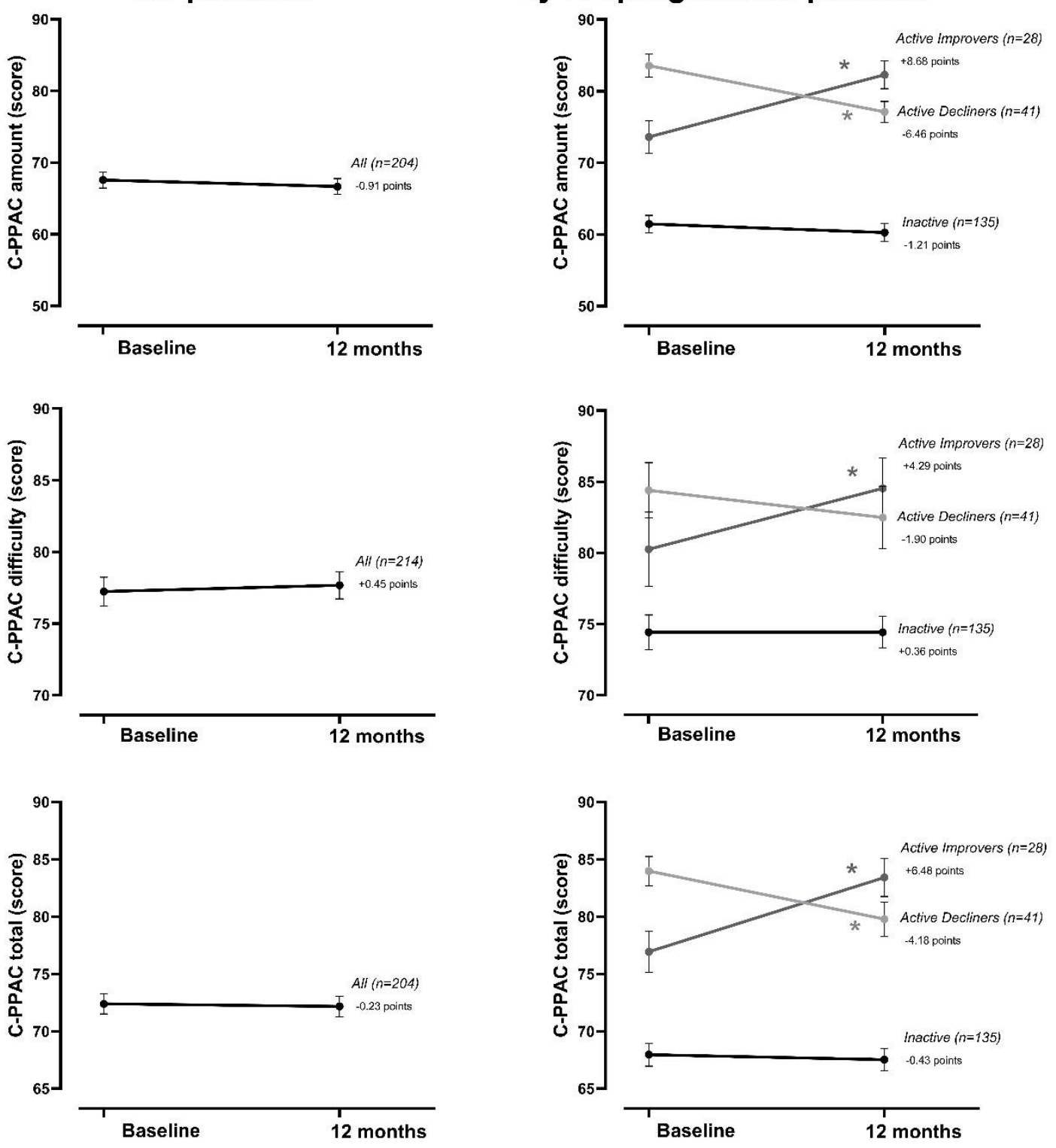
Supplementary data 


\section{Statistical analysis full version}

We compared the baseline characteristics of patients with follow-up vs those lost to follow-up by descriptive statistics and obtained p-values using mixed logistic regression models with random intercepts for study.

We identified cluster groups (physical activity patterns) using k-means (1), a hypothesis-free method that allowed grouping patients based on the baseline level, the final level and the change in daily step count. We used the Calinski-Harabasz stopping rule to decide the number of clusters (2). To characterize the patterns, we described physical activity and physical activity experience variables according to the cluster groups and compared baseline to follow-up values by paired t-tests. Because both studies used the same data collection methods main results are based on the pooled dataset and corrected for study.

To assess determinants of physical activity progression patterns, we first compared subjects' characteristics by physical activity patterns and obtained $p$-values from mixed logistic regression models with random intercepts for study and city area to account for possible heterogeneity in unmeasured characteristics related to study and city area. Then we built a multivariable multinomial regression model using the generalized linear latent and mixed model, with also random intercepts for study and city (3). Model building combined step-forward and backward algorithms, and determinants were included in the final model if: (i) they related to the outcome with a $p$-value $<0.05$; or (ii) they modified (>10\% change in regression coefficient) the estimates of the remaining variables in the model (4). We tested goodness of fit of the final model. 
We performed the following sensitivity analyses: (1) to investigate a possible difference between the two study samples, cluster analysis and description of resulting patterns was performed separately for both samples; (2) to test whether the observed patterns were due to changes in wearing time, we tested the association between the change in daily step count and the change in wearing time overall and per pattern; (3) to rule out a relevant effect of pulmonary rehabilitation on the physical activity patterns we repeated the clustering after excluding patients included in pulmonary rehabilitation programs at baseline and/or during follow-up.

We estimated that the available sample size $(n=291)$, fixed by the primary objectives of the original studies, was sufficient to identify physical activity patterns using cluster kmeans, as our ratio of number of subjects to number of variables $(291 / 3=97)$ was much higher than the 0.01 often used for the same analysis in other contexts $(5,6)$.

Due to the small proportion of missing data $(<2 \%$ of total data), we used a complete case strategy and reported missing data in the table footnotes.

All analyses were conducted using Stata/SE 14.2 (StataCorp, College Station, TX, USA). 
Figure S1 Flow of participants through the study.

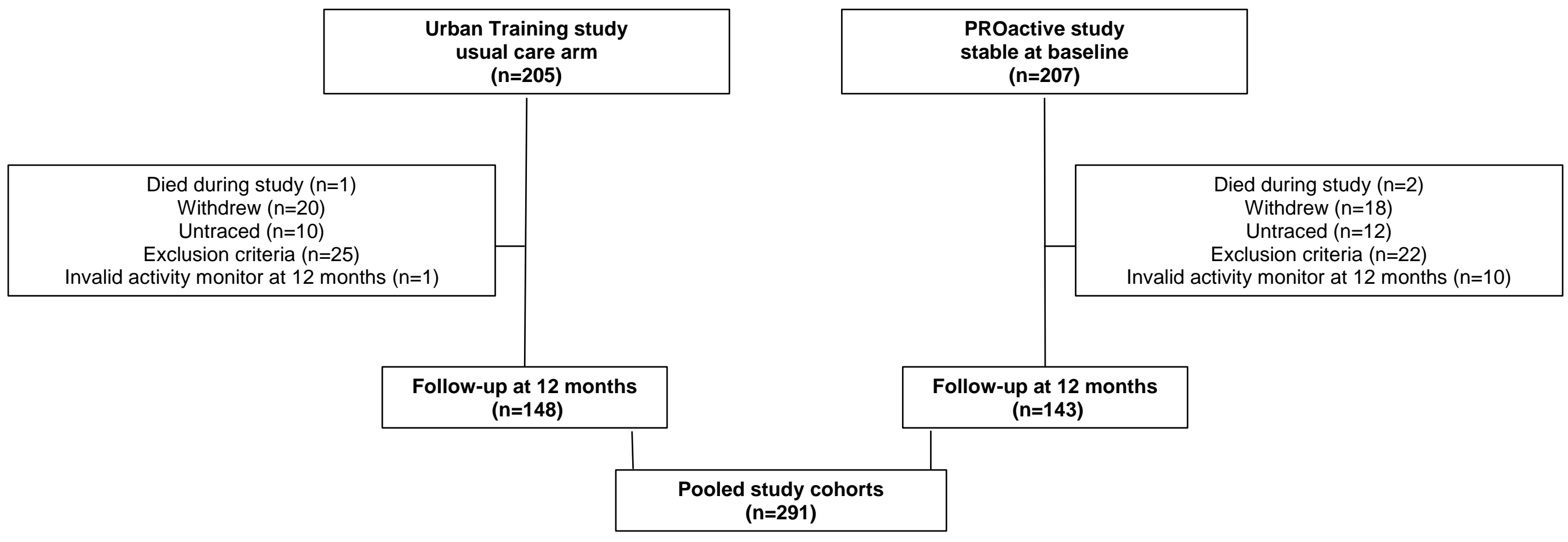


Table S1 Patient characteristics at baseline for all patients (Urban Training and PROactive study, $n=412$ ) and for patients with 12-month follow-up vs lost-to follow-up.

\begin{tabular}{|c|c|c|c|c|}
\hline & All patients & Follow-up & $\begin{array}{l}\text { Lost-to } \\
\text { follow-up }\end{array}$ & $\begin{array}{c}\text { p- } \\
\text { value }^{b}\end{array}$ \\
\hline & $\begin{array}{l}n=412 \\
(100 \%)\end{array}$ & $\begin{array}{c}\mathrm{n}=291^{\mathrm{a}} \\
(71 \%)\end{array}$ & $\begin{array}{c}\mathrm{n}=121^{\mathrm{a}} \\
(29 \%)\end{array}$ & \\
\hline \multicolumn{5}{|l|}{ Sociodemographic } \\
\hline Age (years) & $68 \pm 8$ & $68 \pm 8$ & $68 \pm 8$ & 0.745 \\
\hline Sex (men) & $316(77)$ & $237(81)$ & $79(65)$ & 0.001 \\
\hline Current smoker (yes) & $77(19)$ & $52(18)$ & $25(21)$ & 0.508 \\
\hline Pack-years & $58 \pm 41$ & $58 \pm 41$ & $60 \pm 41$ & 0.684 \\
\hline Education, high school or higher & $236(57)$ & $168(58)$ & $68(56)$ & 0.746 \\
\hline \multicolumn{5}{|l|}{ Interpersonal } \\
\hline Living with a partner $^{c}$ & $291(71)$ & $216(74)$ & $75(63)$ & 0.016 \\
\hline Active worker ${ }^{d}$ & $47(11)$ & $36(12)$ & $11(9)$ & 0.342 \\
\hline Grandparenting $^{\mathrm{e}}$ & $89(43)$ & $67(45)$ & $22(39)$ & 0.389 \\
\hline Dog walking ${ }^{e}$ & $26(13)$ & $20(14)$ & $6(11)$ & 0.566 \\
\hline \multicolumn{5}{|l|}{ Environmental } \\
\hline \multicolumn{5}{|l|}{ Recruitment season } \\
\hline Spring & $55(13)$ & $35(12)$ & $20(16)$ & \multirow{4}{*}{0.161} \\
\hline Summer & $82(20)$ & $58(20)$ & $24(20)$ & \\
\hline Fall & $218(53)$ & $154(53)$ & $64(53)$ & \\
\hline Winter & $57(14)$ & $44(15)$ & $13(11)$ & \\
\hline $\begin{array}{l}\text { Urban vulnerability index (from } 0 \text {-lowest to } 1 \text { - } \\
\text { highest) }\end{array}$ & $0.642 \pm 0.178$ & $0.637 \pm 0.175$ & $0.655 \pm 0.186$ & 0.514 \\
\hline \multicolumn{5}{|l|}{ Clinical } \\
\hline $\mathrm{FEV}_{1}(\%$ predicted $)$ & $57.7 \pm 18.9$ & $58.6 \pm 19.3$ & $55.6 \pm 17.9$ & 0.140 \\
\hline \multirow{2}{*}{\multicolumn{5}{|c|}{ Airflow limitation severity (post-bronchodilator $\mathrm{FEV}_{1}$ ) }} \\
\hline & & & & \\
\hline GOLD 1: Mild (FEV $1 \geq 80 \%$ predicted) & $52(13)$ & $39(13)$ & $13(11)$ & \multirow{4}{*}{0.259} \\
\hline GOLD 2: Moderate $\left(50 \% \leq \mathrm{FEV}_{1}<80 \%\right.$ predicted $)$ & $207(50)$ & $147(51)$ & $60(50)$ & \\
\hline GOLD 3: Severe $\left(30 \% \leq \mathrm{FEV}_{1}<50 \%\right.$ predicted $)$ & $125(30)$ & $88(30)$ & $37(30)$ & \\
\hline GOLD 4: Very Severe ( FEV $1<30 \%$ predicted) & $28(7)$ & $17(6)$ & $11(9)$ & \\
\hline 6MWD (meters) & $461 \pm 109$ & $477 \pm 103$ & $421 \pm 111$ & $<0.001$ \\
\hline CAT score $(0-40)$ & $13.3 \pm 7.5$ & $12.9 \pm 7.6$ & $14.2 \pm 7.3$ & 0.094 \\
\hline CCQ score $(0-6)$ & $1.59 \pm 0.98$ & $1.55 \pm 0.98$ & $1.69 \pm 0.98$ & 0.172 \\
\hline C-PPAC amount score $(0-100)$ & $67.8 \pm 16.9$ & $69.0 \pm 15.8$ & $64.2 \pm 19.5$ & 0.024 \\
\hline C-PPAC difficulty score $(0-100)$ & $77.9 \pm 14.9$ & $78.4 \pm 14.5$ & $76.3 \pm 16.0$ & 0.269 \\
\hline C-PPAC total score $(0-100)$ & $72.8 \pm 13.6$ & $73.7 \pm 12.8$ & $70.3 \pm 15.4$ & 0.044 \\
\hline mMRC score $(0-4)$ & $1.4 \pm 1.0$ & $1.3 \pm 0.9$ & $1.7 \pm 1.1$ & $<0.001$ \\
\hline $\begin{array}{l}\text { Any COPD exacerbation with hospital admission in } \\
\text { previous } 12 \text { months }\end{array}$ & $49(12)$ & $34(12)$ & $15(13)$ & 0.781 \\
\hline $\mathrm{BMI}\left(\mathrm{kg} / \mathrm{m}^{2}\right)$ & $27.7 \pm 5.2$ & $27.6 \pm 4.6$ & $28.1 \pm 6.3$ & 0.306 \\
\hline FFMI $\left(\mathrm{kg} / \mathrm{m}^{2}\right)$ & $18.8 \pm 3.2$ & $19.0 \pm 3.0$ & $18.4 \pm 3.5$ & 0.086 \\
\hline Cardiovascular disease ${ }^{g}$ & $240(59)$ & $176(60)$ & $64(54)$ & 0.212 \\
\hline Ischemic heart disease ${ }^{g}$ & $40(10)$ & $29(10)$ & $11(9)$ & 0.823 \\
\hline Diabetes mellitus ${ }^{\mathrm{g}}$ & $73(18)$ & $51(18)$ & $22(18)$ & 0.817 \\
\hline LABA or LAMA, alone & $56(14)$ & $41(14)$ & $15(13)$ & 0.686 \\
\hline Inhaled corticosteroid with LABA and/or LAMA & $256(63)$ & $179(62)$ & $77(65)$ & 0.557 \\
\hline Pulmonary rehabilitation at baseline & $25(6)$ & $15(5)$ & $10(8)$ & 0.233 \\
\hline Knowledge of baseline PA & $24(6)$ & $19(7)$ & $5(4)$ & 0.348 \\
\hline \multicolumn{5}{|l|}{ Psychological } \\
\hline Anxiety (HAD-A, 0-21) & $5 \pm 4$ & $5 \pm 4$ & $6 \pm 4$ & 0.117 \\
\hline Depression (HAD-D, 0-21) & $4 \pm 3$ & $4 \pm 3$ & $4 \pm 4$ & 0.210 \\
\hline \multicolumn{5}{|l|}{ Physical activity } \\
\hline Step count (steps/day) & $6415 \pm 3678$ & $6720 \pm 3667$ & $5682 \pm 3613$ & 0.010 \\
\hline $\begin{array}{l}\text { Time in moderate-to-vigorous physical activity ( } \geq 3 \\
\text { METs; } \mathrm{min} / \text { day) }\end{array}$ & $95.8 \pm 45.9$ & $99.4 \pm 45.3$ & $87.0 \pm 46.2$ & 0.013 \\
\hline Intensity during walking $\left(\mathrm{m} / \mathrm{s}^{2}\right)$ & $1.84 \pm 0.31$ & $1.86 \pm 0.31$ & $1.80 \pm 0.30$ & 0.050 \\
\hline Sedentary time (h/day) & $10.53 \pm 1.93$ & $10.53 \pm 1.94$ & $10.52 \pm 1.92$ & 0.961 \\
\hline
\end{tabular}


Notes: Data are presented as $\mathrm{n}(\%)$, mean \pm SD.

aSome variables have missing values, as follows. Follow-up: 1 in education, 1 in living with a partner, 1 in CAT total, 1 in CCQ score, 31 in C-PPAC scores, 1 in any COPD exacerbation with hospital admission in previous 12 months, 26 in FFMI, 3 in LABA or LAMA, alone, 3 in inhaled corticosteroid with LABA and/or LAMA, 3 in HAD anxiety and depression; Lost-to follow-up: 1 in living with a partner, 1 in 6MWD, 33 in C-PPAC scores, 3 in any COPD exacerbation with hospital admission in previous 12 months, 5 in FFMI, 2 in ICD10 codes: 100 to 199 for Cardiovascular diseases; I20 to I25 for Ischemic heart disease, E14 for Diabetes mellitus, 3 in LABA or LAMA, alone, 3 in inhaled corticosteroid with LABA and/or LAMA, 1 in HAD depression.

b $\mathrm{p}$-value from mixed logistic regression models with random effects for study (Urban Training and PROactive), due to small numbers random effects for city area were not applied.

${ }^{c}$ marital status: living with a partner vs single, widowed or divorced.

dworking status: active worker (working full-time or part-time) vs. unemployed, housework or retired.

eonly available for Urban Training.

'The urban vulnerability index is a measure of socioeconomic status at the census tract level that combines demographic, economic, residential and subjective indicators, and ranges from lowest [0] to highest [1] level of neighborhood vulnerability.

9ICD10 codes: 100 to 199 for cardiovascular diseases; I20 to I25 for ischemic heart disease, E14 for diabetes mellitus. Abbreviations: $F E V_{1}$ : forced expiratory volume in 1 second; FVC: forced vital capacity; GOLD: Global Initiative for Chronic Obstructive Lung Disease; 6MWD: 6-min walking distance; CAT: COPD Assessment Test; CCQ: Clinical COPD Questionnaire; C-PPAC: Clinical visit-PROactive Physical Activity in COPD (higher numbers indicate a better score); mMRC: modified Medical Research Council; BMI: body mass index; FFMI: fat free mass index; LABA: long-acting beta $2_{2}^{-}$ agonists; LAMA: long-acting anti-muscarinics; HAD-A: Hospital Anxiety and Depression scale - Anxiety; HAD-D: Hospital Anxiety and Depression scale - Depression; MET: metabolic equivalent of task. 
Table S2 Physical activity and physical activity experience variables at baseline and at 12-month follow-up, overall and by PA progression pattern (Inactive, Active Improvers and Active Decliners).

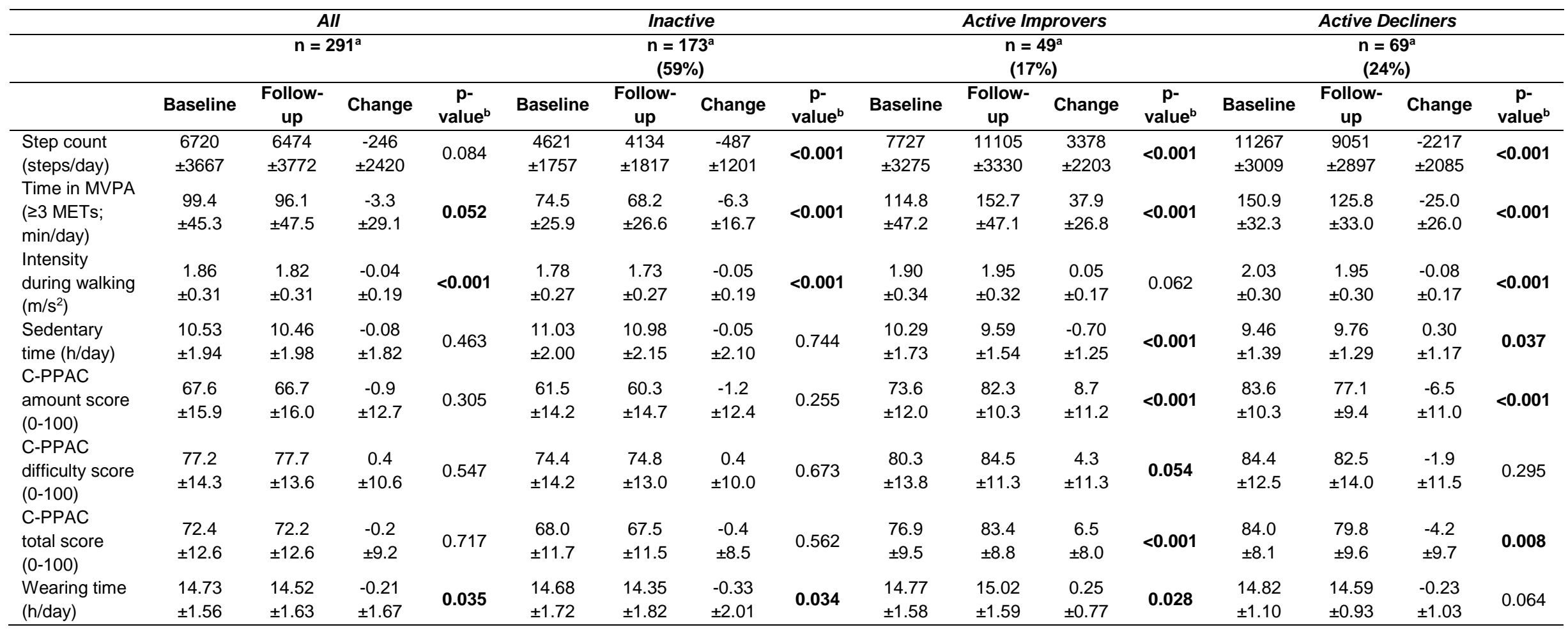

Notes: Data are presented as mean \pm SD. For C-PPAC variables means and p-values are reported for patients with data at baseline and follow-up.

${ }^{a} C$-PPAC variables have 87 missing values: 38 in Inactive, 21 in Active Improvers, and 28 in Active Decliners.

bpaired t-test.

Abbreviations: MVPA: moderate-to-vigorous physical activity; MET: metabolic equivalent of task; C-PPAC: Clinical visit-PROactive Physical Activity in COPD (higher numbers indicate a better score). 
Table S3 Step count (mean steps/day) at baseline and at 12-month follow-up as well as selected variables at baseline, by cluster groups (physical activity progression patterns) identified by k-means, performed separately for the Urban Training and the PROactive study.

\begin{tabular}{|c|c|c|c|c|c|c|c|c|c|c|c|c|c|c|c|}
\hline & \multicolumn{5}{|c|}{ Cluster 1} & \multicolumn{5}{|c|}{ Cluster 2} & \multicolumn{5}{|c|}{ Cluster 3} \\
\hline & $\begin{array}{c}\mathbf{n} \\
\text { (row\%) }\end{array}$ & Baseline & $\begin{array}{l}\text { Follow- } \\
\text { up }\end{array}$ & Change & $\begin{array}{c}\text { p- } \\
\text { value }^{a}\end{array}$ & $\begin{array}{c}n \\
\text { (row\%) }\end{array}$ & Baseline & $\begin{array}{l}\text { Follow- } \\
\text { up }\end{array}$ & Change & $\begin{array}{c}\text { p- } \\
\text { value }^{a}\end{array}$ & $\begin{array}{c}n \\
\text { (row\%) }\end{array}$ & Baseline & $\begin{array}{l}\text { Follow- } \\
\text { up }\end{array}$ & Change & $\begin{array}{c}\text { p- } \\
\text { value }^{a}\end{array}$ \\
\hline \multicolumn{16}{|l|}{ Urban Training } \\
\hline $\begin{array}{l}\text { Step count } \\
\text { (steps/day) }\end{array}$ & $\begin{array}{c}79 \\
(54 \%)\end{array}$ & $\begin{array}{c}6028 \\
\pm 2176\end{array}$ & $\begin{array}{c}5125 \\
\pm 2045\end{array}$ & $\begin{array}{c}-903 \\
\pm 1428\end{array}$ & $<0.001$ & $\begin{array}{c}36 \\
(24 \%)\end{array}$ & $\begin{array}{c}6722 \\
\pm 2491\end{array}$ & $\begin{array}{r}10435 \\
\pm 2293\end{array}$ & $\begin{array}{c}3713 \\
\pm 2288\end{array}$ & $<0.001$ & $\begin{array}{c}33 \\
(22 \%)\end{array}$ & $\begin{array}{l}13144 \\
\pm 3340\end{array}$ & $\begin{array}{l}11442 \\
\pm 3606\end{array}$ & $\begin{array}{l}-1702 \\
\pm 2754\end{array}$ & 0.001 \\
\hline Age (years) & & $69 \pm 8$ & & & & & $71 \pm 9$ & & & & & $67 \pm 7$ & & & \\
\hline Sex (men) & & $70(89)$ & & & & & $32(89)$ & & & & & $28(85)$ & & & \\
\hline $\begin{array}{l}\text { FEV }_{1} \\
\text { (\% predicted) }\end{array}$ & & $55.2 \pm 18.2$ & & & & & $62.6 \pm 15.5$ & & & & & $60.5 \pm 17.3$ & & & \\
\hline 6MWD (meters) & & $485 \pm 87$ & & & & & $519 \pm 83$ & & & & & $517 \pm 68$ & & & \\
\hline $\begin{array}{l}\text { mMRC score } \\
(0-4)\end{array}$ & & $1.2 \pm 0.9$ & & & & & $1.1 \pm 0.8$ & & & & & $0.8 \pm 0.7$ & & & \\
\hline \multicolumn{16}{|l|}{ PROactive } \\
\hline $\begin{array}{l}\text { Step count } \\
\text { (steps/day) }\end{array}$ & $\begin{array}{c}118 \\
(83 \%)\end{array}$ & $\begin{array}{c}4431 \\
\pm 1735\end{array}$ & $\begin{array}{c}4097 \\
\pm 1891\end{array}$ & $\begin{array}{c}-334 \\
\pm 1098\end{array}$ & 0.001 & $\begin{array}{c}6 \\
(4 \%)\end{array}$ & $\begin{array}{l}11339 \\
\pm 1239\end{array}$ & $\begin{array}{l}14340 \\
\pm 2593\end{array}$ & $\begin{array}{c}3001 \\
\pm 1716\end{array}$ & 0.008 & $\begin{array}{c}19 \\
(13 \%)\end{array}$ & $\begin{array}{l}11188 \\
\pm 1992\end{array}$ & $\begin{array}{c}8222 \\
\pm 2685\end{array}$ & $\begin{array}{l}-2966 \\
\pm 2166\end{array}$ & $<0.001$ \\
\hline Age (years) & & $68 \pm 8$ & & & & & $65 \pm 9$ & & & & & $63 \pm 7$ & & & \\
\hline Sex (men) & & $89(75)$ & & & & & $4(67)$ & & & & & $14(74)$ & & & \\
\hline $\begin{array}{l}\mathrm{FEV}_{1} \\
\text { (\% predicted) }\end{array}$ & & $56.8 \pm 20.7$ & & & & & $68.6 \pm 12.1$ & & & & & $69.8 \pm 21.7$ & & & \\
\hline 6MWD (meters) & & $435 \pm 109$ & & & & & $520 \pm 130$ & & & & & $541 \pm 110$ & & & \\
\hline $\begin{array}{l}\text { mMRC score } \\
(0-4)\end{array}$ & & $1.6 \pm 1.0$ & & & & & $1.0 \pm 0.6$ & & & & & $1.0 \pm 0.8$ & & & \\
\hline
\end{tabular}

Notes: Data are presented as mean $\pm S D$.

apaired t-test.

Abbreviations: FEV $_{1}$ : forced expiratory volume in 1 second; 6MWD: 6-min walking distance; mMRC: modified Medical Research Council. 
Table S4 Correlation between the change in daily step count and the change in wearing time, overall and by PA progression pattern (Inactive, Active Improvers and Active Decliners).

\begin{tabular}{lccc}
\hline & $\mathbf{n}(\%)$ & Pearson correlation coefficient & p-value \\
\hline All patients & $291(100 \%)$ & 0.090 & 0.124 \\
Inactive & $173(59 \%)$ & 0.002 & 0.981 \\
Active Improvers & $49(17 \%)$ & -0.097 & 0.508 \\
Active Decliners & $69(24 \%)$ & 0.162 & 0.184 \\
\hline
\end{tabular}


Table S5 Step count (mean steps/day) at baseline and at 12-month follow-up, by cluster groups (physical activity progression patterns) identified by k-means, performed separately for all patients $(n=291)$ and excluding patients with rehabilitation $(n=270)$.

\begin{tabular}{|c|c|c|c|c|c|c|c|c|c|c|c|c|c|c|c|}
\hline & \multicolumn{5}{|c|}{ Inactive } & \multicolumn{6}{|c|}{ Active Improvers } & \multicolumn{4}{|c|}{ Active Decliners } \\
\hline & $\begin{array}{c}\mathrm{n} \\
\text { (row\%) }\end{array}$ & Baseline & $\begin{array}{l}\text { Follow- } \\
\text { up }\end{array}$ & Change & $\begin{array}{c}\mathrm{p}- \\
\text { value }^{\mathrm{b}}\end{array}$ & $\begin{array}{c}\mathbf{n} \\
\text { (row\%) }\end{array}$ & Baseline & $\begin{array}{l}\text { Follow- } \\
\text { up }\end{array}$ & Change & $\begin{array}{c}\text { p- } \\
\text { value }^{\text {b }}\end{array}$ & $\begin{array}{c}\mathbf{n} \\
\text { (row\%) }\end{array}$ & Baseline & $\begin{array}{l}\text { Follow- } \\
\text { up }\end{array}$ & Change & $\begin{array}{c}\text { p- } \\
\text { value }^{b}\end{array}$ \\
\hline $\begin{array}{l}\text { Step count } \\
\text { (steps/day), } \\
\text { all patients }\end{array}$ & $\begin{array}{c}173 \\
(59 \%)\end{array}$ & $\begin{array}{c}4621 \\
\pm 1757\end{array}$ & $\begin{array}{c}4134 \\
\pm 1817\end{array}$ & $\begin{array}{c}-487 \\
\pm 1201\end{array}$ & $<0.001$ & $\begin{array}{c}49 \\
(17 \%)\end{array}$ & $\begin{array}{c}7727 \\
\pm 3275\end{array}$ & $\begin{array}{l}11105 \\
\pm 3330\end{array}$ & $\begin{array}{c}3378 \\
\pm 2203\end{array}$ & $<0.001$ & $\begin{array}{c}69 \\
(24 \%)\end{array}$ & $\begin{array}{l}11267 \\
\pm 3009\end{array}$ & $\begin{array}{c}9051 \\
\pm 2897\end{array}$ & $\begin{array}{l}-2217 \\
\pm 2085\end{array}$ & $<0.001$ \\
\hline $\begin{array}{l}\text { Step count } \\
\text { (steps/day), } \\
\text { patients with } \\
\text { rehabilitation } \\
\text { excluded }^{\text {a }}\end{array}$ & $\begin{array}{c}154 \\
(57 \%)\end{array}$ & $\begin{array}{c}4544 \\
\pm 1763\end{array}$ & $\begin{array}{c}4003 \\
\pm 1753\end{array}$ & $\begin{array}{c}-541 \\
\pm 1209\end{array}$ & $<0.001$ & $\begin{array}{c}50 \\
(19 \%)\end{array}$ & $\begin{array}{c}7516 \\
\pm 3187\end{array}$ & $\begin{array}{l}10730 \\
\pm 3345\end{array}$ & $\begin{array}{c}3213 \\
\pm 2266\end{array}$ & $<0.001$ & $\begin{array}{c}66 \\
(24 \%)\end{array}$ & $\begin{array}{l}11206 \\
\pm 3033\end{array}$ & $\begin{array}{c}9078 \\
\pm 2928\end{array}$ & $\begin{array}{l}-2128 \\
\pm 1943\end{array}$ & $<0.001$ \\
\hline
\end{tabular}

Notes: Data are presented as mean \pm SD

apatients in pulmonary rehabilitation at baseline and/or follow-up were excluded $(n=21)$

bpaired t-test 


\section{References:}

1. Genolini, Christophe Falissard B. KmL: k-means for longitudinal data. Comput Stat 2010;25:317-328.

2. Calinski T, Harabasz J. A dendrite method for cluster analysis. Commun Stat Theory Methods 1974;3:1-27.

3. Rabe-Hesketh S, Skrondal A, Pickles A. Maximum likelihood estimation of limited and discrete dependent variable models with nested random effects. J Econom 2005;128:301-23.

4. Hosmer DW, Lemeshow S, Sturdivant RX. Applied logistic regression. 3rd ed. Hoboken, New Jersey: John Wiley \& Sons; 2013.

5. Wang Y, Miller DJ, Clarke R. Approaches to working in high-dimensional data spaces: Gene expression microarrays. Br J Cancer 2008;98:1023-8.

6. Garge NR, Page GP, Sprague AP, Gorman BS, Allison DB. Reproducible clusters from microarray research: Whither? BMC Bioinformatics 2005;6:S10. 